\title{
汶川-映秀 $M_{\mathrm{S}} 8.0$ 地震的地球物理场与动力过程
}

滕吉文 ${ }^{1,2,3^{*}}$, 宋鹏汉 ${ }^{1,3}$, 刘有山 ${ }^{1}$

1. 中国科学院地质与地球物理研究所, 北京 100029 ;

2. 吉林大学地球探测科学与技术学院, 长春 130026 ;

3. 中国科学院大学, 北京 100049

*联系人, E-mail: jwteng@mail.iggcas.ac.cn

2018-04-24 收稿, 2018-05-15 修回, 2018-05-17 接受, 2018-06-28 网络版发表

国家重点基础研究发展计划(2008CB425700)和国家科技支撑计划(0907804078)资助

摘要汶川-映秀 $M_{\mathrm{S}} 8.0$ 大地震发生在当今构造、地震远不如相邻地带的龙门山断裂系上, 震间和震后在地表形 成了一条长3 $00 \mathrm{~km}$, 宽近80 km, 发生了70000多次余震的长廊地带, 造成了严重的地表破坏和大量人员伤亡, 而 震前却未见到可视为与大地震发生与发展有因果关系的征兆现象, 可是大地震就在这里发生了. 多年的研究表明, 这次 $M_{\mathrm{S}} 8.0$ 大地震的发生乃是由于印度洋板块与欧亚板块碰撞、挤压，且东构造结向北“顶进”插入青藏高原东北缘 力系作用下导致的该区构造、地震均强烈活动, 在此背景下: (1) 高原腹地壳、幔物质向东运移受阻、应力集中, 深 部物质重新分异、调整, 物质与能量进行强烈交换; (2) 震源深处介质属性与结构变异、破裂, 且导致重力场的高 度不均衡; (3) 川西高原, 相对低速壳、幔物质在坚硬的四川盆地壳、幔物质阻隔下, 沿龙门山陡峭主断裂面相上 逆冲, 并在龙门山3条不同角度西倾断裂向下收玫处强烈碰撞; (4) 震源深处汇聚断裂的形成构成了汶川-映秀 $M_{\mathrm{S}} 8.0$ 大地震的发震断裂.

关键词汶川-映秀 $M_{\mathrm{S}} 8.0$ 大地震, 物质与能量交换, 壳、幔结构突变, 重力不均衡, 深部汇聚断裂带-发震断裂

龙门山断裂系是青藏高原与扬子克拉通的界 带 $^{[1]}$, 可是在该大地震 $\left(M_{\mathrm{S}} 8.0\right)$ 发生前, 龙门山断裂系 上构造、地震并不活动 ${ }^{[2-5]}$. 2008年5月 12 日在四川盆 地北缘, 青藏高原东北缘的汶川-映秀 $M_{\mathrm{S}} 8.0$ 大地震的 发生至今已近 10 年了, 在这 10 年间有关这次大地震 孕育、发展和发生备受地球科学界的广泛关注. 至今 在中外各种期刊上发表的的论文数量是十分可观的, 初步概略的估算至少有300 400篇. 纵观这一系列的 文章, 确显百花齐放、百家争鸣, 各自具有其论点和 论据. 这对人们深化理解这次大地震孕育、发展、发 生和厘定其真正的原由是十分重要的记载. 为此, 10 年来我一直在思考着汶川-映秀 $M_{\mathrm{S}} 8.0$ 大地震发生的 表象、内核, 派生现象与本质以及它们的耦合响应,
物质运动的轨迹与其深层动力过程, 试图提出一个 可为共识或优势共识的逼近理念或概念模式.

汶川-映秀大地震发生在两大陆板块碰撞、挤压, 东构造结向北扦人的大地构造极为活动的地带, 引 发了地表的诸多派生现象. 对于汶川-映秀大地震发 生的推断, 普遍认为其主震、强余震和众多余震应发 生在龙门山断裂系的某条断层上, 但根据第四纪以 来该区的构造活动等地质现象做出的推断和认识并 不一致 ${ }^{[3,4,6 ~ 26]}$, 此外对GPS测量结果的理解也不完全 统一 ${ }^{[13,27,28]}$. 地球物理工作者在这次大地震发生前后 也给出了这一地区的中、下地壳低S波速和低黏滞系 数和低电阻率等下地壳塑性流模型 ${ }^{[7,28 ~ 43]}$, 这对汶川映秀大地震的震源研究和周边地带破裂效应导致该 
大地震的发生和发展确有深刻的认识 ${ }^{[27,44 \sim 52]}$.

应当清晰地认识到, 青藏高原的短缩增厚不能 表征高原东北缘的构造活动, 而东北缘的构造与地 震活动也不能表明龙门山地带深部下地壳物质的流 动特征. 有人提出青藏高原东北缘上地幔的短缩是 东缘隆升的主要原因 ${ }^{[4,15]}$, 但证据显然是不充分的. 因为高精度的人工源地震壳、幔深部探测揭示出龙门 山地带的地壳各层结构与地形起伏是同幅度突变 的 ${ }^{[27,39,53,54]}$.

在青藏高原东北缘的相邻地域, 采用不同的地 球物理方法, 如人工源地震深部探测 [5,26,42,55 65]、天 然地震方法等 ${ }^{[24,60,65 ~ 83]}$ 做了大量研究. 尽管一系列 的方法 ${ }^{[84 ~ 87]}$ 各自得到了结果, 并进行了研讨. 但至 今对青藏高原北缘的壳、幔结构尚未能取得共识, 究 其原因之一, 即方法本身固有的精度与缺陷, 尚难以 给出逼近于实况的量化解释; 原因之二, 虽然人们均 承认, 也强调高精度, 但若观测精度不高, 数据采集 的分辨率不高, 则不可能获取精细结构, 而轮廓性的 工作做多了, 反而对真正高精度的结果未能给予权 重; 原因之三, 仅有对彩色图像的定性推断或分析, 而对物理理念、属性、波场精度、方法和异常原因均 尚缺乏理性的解释. 因为不同的地球物理方法其固 有的优点与缺陷, 观测精度与分辨率图像解的不唯 一性均有很大差异, 特别是对外国人提出的论点与 论据, 解译与理解要给予深人的思考, 而不应是汼强 与简单的附和以及理念依据不充分的推断 ${ }^{[88]}$.

由于至今人们对强烈地震，特别是大地震孕育、 发生和发展的深层过程和机制尚处在探索阶段, 故 一次大地震发生后, 从不同的方法、不同的地表派生 现象出发, 势必可以在不同研究领域与视野提出各 种认识. 尽管均有其逻辑上的可取之处, 但是远远不 够的. 因为汶川-映秀 $M_{\mathrm{S}} 8.0$ 大地震的孕育、发展和发 生远非可依宏观的方法、地表派生现象和地震震中位 置落于某断层上等可以理解的. 同时下地壳流与这 次大地震的发生关系却非如此简单, 亦非理想的与 不充分边界条件约束下的初始模型提取及数值模拟 可以逼近的. 这便表明, 必须依据高精度的地面地球 物理观测, 高分辨率的数据采集和误差约束在千米 级范围内的结构精细刻化来研究与探索强烈地震和 大地震震源深处及其周边地域的介质物理属性、结 构、深部环境和物质, 与能量交换的深层过程, 以达 厘定深部发震断裂和震源体积及其动力学响应.
基于这样的前提，本文将讨论以下几个问题：(1) 龙门山断裂系地域重力场的高度不均衡; (2) 龙门山 地带壳、幔精细结构突变的深层过程; (3) 汶川-映秀 $M_{\mathrm{S}} 8.0$ 大地震孕育与发生的力源机制.

\section{1 龙门山断裂系地域重力场的高度不均衡}

我国川滇地域大地构造十分复杂, 其界域为: 北 以西秦岭北缘断裂带和东昆仑断裂带所辖地域为界, 西与高黎贡山相隔, 东与四川盆地相连, 南以东南亚 诸国为邻(图1(a)). 在这一广域内主体构造是西侧的 鲜水河断裂系, 且构造、地震强烈活动; 北部的昆仑 断裂带, 西秦岭北缘断裂带与近 NS 向的岷山断裂, 虎牙断裂构造地震亦均十分活跃; 南部的安宁河-侧 本河断裂-小江断裂带则为南北构造带中，为构造与 地震活动地带; 且均曾有 $M \geqslant 7$ 级的强烈地震发生. 相对周边而言, 唯有龙门山断裂系所辖地域现今构 造和地震活动均不如四邻, 即未发生过 $M \geqslant 6$ 的地 震 ${ }^{[27]}$. 显见，地表的构造活动、地震活动尚难以预测 潜在地震发生的可能, 可是 8 级大地震确实在这里发 生了.

为此必须去追索能够反映深部物质重新分异、调 整和运移的重力场图像.

\section{1 龙门山构造带地域与其周边相比，在重力边 界场特征上十分独特}

基于在 $98^{\circ} \sim 110^{\circ} \mathrm{E}, 24^{\circ} \sim 34^{\circ} \mathrm{N}$ 范围内的川滇地带 的自由空气异常和布格重力异常数据, 及其分布特 征均呈现出龙门山断裂系与其南北两侧的明显差异 (图1(b)).

该地域的重力场分区明显，即基本上呈西北低、 东南高的势态展布, 地形与布格重力异常呈正相关, 反映了川滇地区深部物质分异、调整和地壳厚度变化

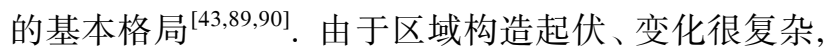
且在布格重力异常上面叠加了强度不等的各种局部 异常, 它们是地壳内部不同尺度密度不均匀体的反 映 ${ }^{[43,77,89,91 ~ 97]}$, 并进行了横向构造分析 ${ }^{[98,99]}$.

龙门山造山带是一条重力异常显著变化的陡梯 度带100 350 mGal(图1(b)和(c)), 即为一个高梯度变 异带. 在 $30^{\circ} \mathrm{N}, 102^{\circ} \mathrm{E}$ 的附近有一局部扭动(即康定附 近); 在 $31.5^{\circ} \mathrm{N}, 104^{\circ} \mathrm{E}$ 附近(即在汶川附近)也存在局 部扭动; 然后在 $33^{\circ} \mathrm{N}, 105^{\circ} \mathrm{E}$ 以北地带发散，这可能 与岷山-虎牙断裂地带的构造响应相关. 该地带的布 
(a)

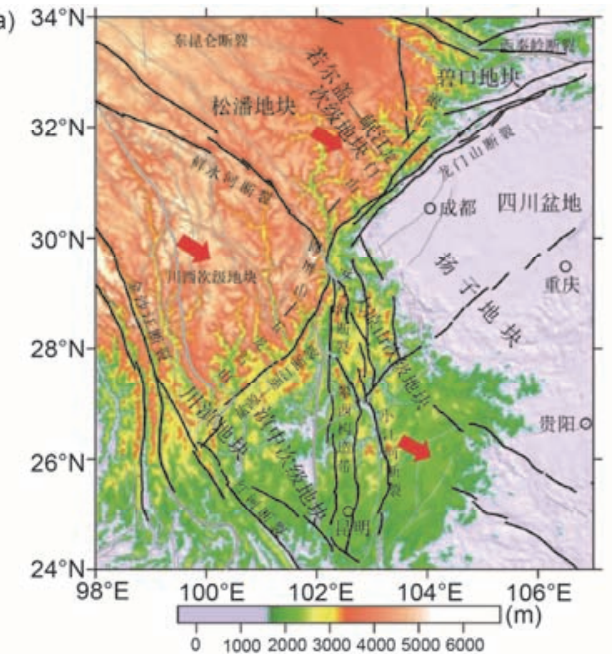

(b)

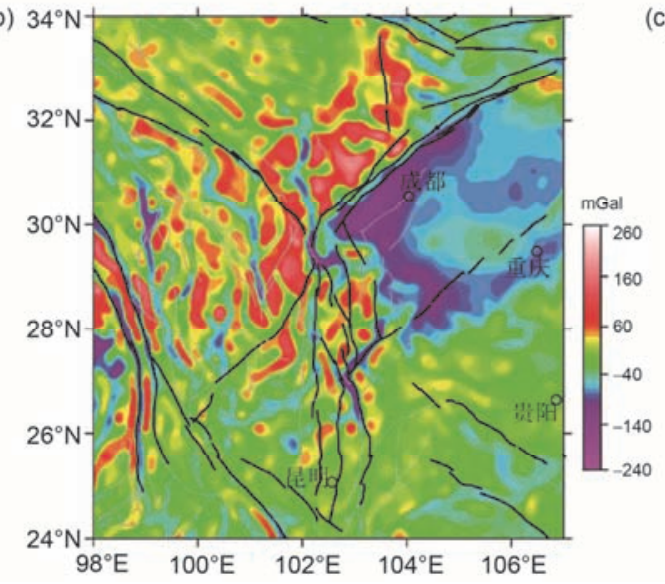

(c)

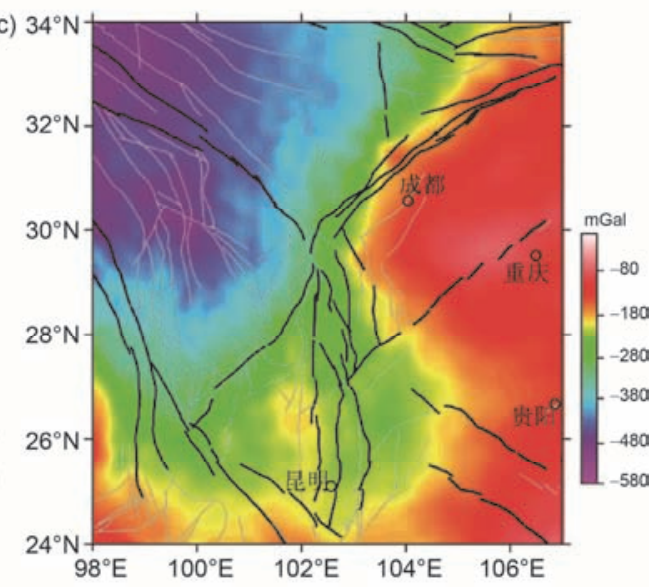

图 1 青藏高原东北缘重力场特征与边界场响应分布图 ${ }^{[43]}$. (a) 概略区域构造; (b) 自由空气重力异常; (c) 布格重力异常

Figure 1 Distribution maps for the gravity field and response of boundary in the Tibet Plateau's northeastern margin. (a) Schematic diagram; (b) free-space gravity anomaly; (c) Bouguer gravity anomaly

格重力异常场展布表明: 它基本上可分为南段 $\left(30^{\circ} \mathrm{N}, 103^{\circ} \mathrm{E} 31.5^{\circ} \mathrm{N}, 104^{\circ} \mathrm{E}\right)$ 和北段 $\left(31.5^{\circ} \mathrm{N}, 104^{\circ} \mathrm{E} \sim\right.$ $33^{\circ} \mathrm{N}, 106^{\circ} \mathrm{E}$ )两部分. 在龙门山断裂系以南(实为东 南)四川盆地广大地区布格重力异常值为 $-80 \times 10^{-5}$ $-200 \times 10^{-5} \mathrm{~m} / \mathrm{s}^{2}$, 而在龙门山断裂系以北(实为西北) 则布格重力异常为更负的地带, 即 $-400 \times 10^{-5}$ $-300 \times 10^{-5} \mathrm{~m} / \mathrm{s}^{2}$. 特别是在龙门山断裂系西南端到东 北端是一个重力梯度逐渐减小的发散地带, 而龙门 山断裂系的南北两段则均为高梯度变化带.

在龙门山造山带地域, 即其西南端和东北端布 格重力异常所反映的格局表明: 沿龙门山造山带, 重 力梯度 $>1 \times 10^{-5} \mathrm{~m} / \mathrm{s}^{2}$, 四川盆地 $<1 \times 10^{-5} \mathrm{~m} / \mathrm{s}^{2}$, 青藏高 原东北缘亦 $\leqslant 1 \times 10^{-5} \mathrm{~m} / \mathrm{s}^{2}$, 而在龙门山造山带, 特别 是北川地带竟高达 $2.0 \times 10^{-5} \mathrm{~m} / \mathrm{s}^{2}$ 以上, 故表明这里是
一个深部物质重新分异、调整与能量强烈交换的地带.

\section{2 壳、幔介质与结构的密度分布}

对于地壳浅部, 即中、上地壳的密度分布, 可利 用地壳内部平均密度扰动的反演进行探讨, 并进一 步分析地壳中、上部和深部的岩性和构造差异. 浅部 重力异常的视密度分布(图S1(a))反映的是中、上地壳 介质的密度变化. 四川盆地内部中、上地壳密度较高, 异常走向与龙门山造山带基本一致, 而整个松潘-甘 孜地带则密度较低. 由图S1(a)可见, 龙门山造山带 恰分布在正负密度异常相汇聚的边界上, 且位于密 度较高的一侧, 反映出松潘-甘孜地带的中、上地壳 密度较低的深部物质向ES方向运移, 且与深部壳、幔 物质较高密度的四川盆地之间呈逆掩推覆关系, 而 
龙门山造山带在深部则向WN方向呈缓慢倾斜.

对于壳、幔深部物质, 图S1(b)显示了深部重力异 常的视密度分布, 反映了更深处, 即下地壳与上地幔 顶部的密度分布特征. 显而易见, 四川盆地深部亦为 高密度区, 但高密度分布的位置与浅部存在一定差 异. 浅部高密度区与盆地的几何轮廓一致, 而深部高 密度区则不在盆地正下方, 而是在盆地南部 $30^{\circ} \mathrm{N}$ 附 近. 这表明盆地下方为由密度较高的坚硬物质组成, 即与高速度体和高阻体一致. 正是这下地壳与上地 幔顶部坚硬的 “刚性” 块体阻挡了青藏高原东北缘深 部壳、幔物质的东向流展, 且迫使其转而向南部, 即 一部分向SSE运移、而后又向南流展. 同时在强烈挤 压作用下，深部下地壳和上地幔盖层物质同步“流 动”并向上运移.

松潘-甘孜地带下面地壳厚度大, 而其上地幔顶 部Pn波速度偏低与其NNE向低密度体相对应. 深部 与浅部介质密度的差异, 反映出四川盆地深部高密 度体的“刚性”阻挡, 而在深部形成低密度物质的堆 积, 故下地壳增厚. 该区深、浅构造之间的密度显著 差异表明, 下地壳和地幔物质在受力作用下, 在其运 移过程中与上部上、中地壳解耦.

\section{3 重力场的高梯度变化与重力场的高度不均衡 状态}

(i ) 垂直于龙门山断裂系两条最新高精度测量 剖面的异常地壳均衡厚度分布. 依据两条高精度重 力测量的地壳厚度 $(M)$ 与依据Airy均衡理论确定的不 同高程时理论均衡地壳厚度 $(D)$ (图2(a)) 在均衡条件

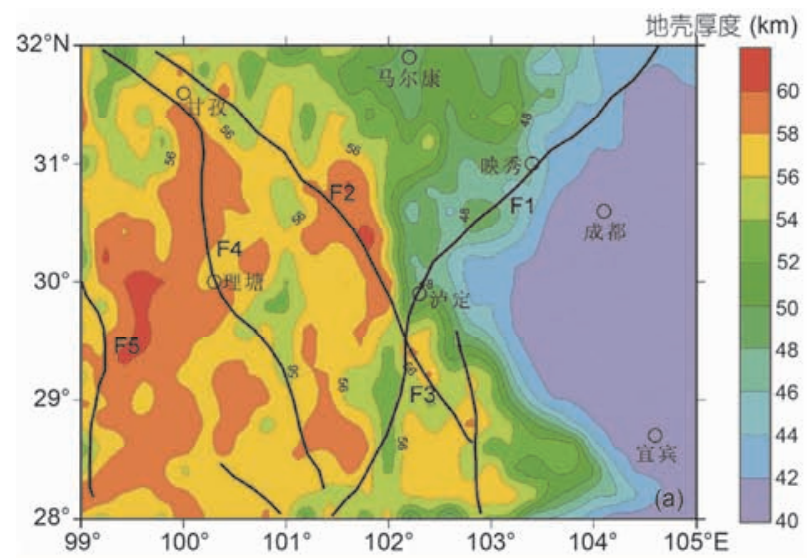

不是相等值. 若存在差异 $(D-M)$ 则表明未达均 衡 ${ }^{[92,93,100,101]}$ ，二者差异越大，则标志着该地带的深 部介质越处于不均衡状态(图2). 反演结果表明. 四 川盆地基本上处于均衡状态, 龙门山-岷山地区 $D-M$ 可达8 10 km, 差异巨大, 标志着这一地带地壳恰处 于不均衡状态，即地壳介质与结构均处于极不稳定 状态, 川西高原地区 $D-M$ 为几千米, 即表征着这里 呈略不平衡状态.

(ii) 龙门山及其相邻地域的均衡重力异常特征. 基于重力均衡表征着地表起伏与地下介质密度分布 的综合效应, 而研究区均衡重力异常可分为 3 个 区 $^{[92,93,100,102]}$ : 即青藏高原东部弱负均衡重力异常区 ( I )、龙门山正均衡异常区 (II) 和四川盆地负均衡重 力异常区 (III)(图3). 青藏高原东部 I 区负均衡重力 异常值为 $-10 \times 10^{-5} \sim-20 \times 10^{-5} \mathrm{~m} / \mathrm{s}^{2}$, 龙门山地带为 $0 \sim$ $125 \times 10^{-5} \mathrm{~m} / \mathrm{s}^{2}$, 为正值, 并在其内部存在 $125 \times 10^{-5}$ 和 $135 \times 10^{-5} \mathrm{~m} / \mathrm{s}^{2}$ 的正重力异常圈闭, 四川盆地 II 区为 $0 \sim 60 \times 10^{-5} \mathrm{~m} / \mathrm{s}^{2}$, 即为负值区, 并形成 $-40 \times 10^{-5} \sim$ $-50 \times 10^{-5} \mathrm{~m} / \mathrm{s}^{2}$ 的负异常圈闭. 显见龙门山造山带( II 区)重力远未达均衡, 异常差值可达 $185 \times 10^{-5} \mathrm{~m} / \mathrm{s}^{2}$. 均衡重力异常带 (II 区) 又以理县-都江堰为界将其分 为南段 $(A)$ 与北段 $(B)$.

(iii) 深部物质与能量的强烈交换与重力异常场 突变. 龙门山造山带的特异重力场呈现及其与周缘 各地的显著差异表明, 龙门山地带的壳、幔深处物质 在进行着重新分异、调整和运移, 并导致了这一地带 深部物质与能量的强烈交换, 故促使：(1) 布格重力 场呈现出突显的区、带展布，反映出龙门山地带重力

图 2 理论地壳均衡厚度(a)和地壳厚度的均衡差异程度(b)分布图 ${ }^{[96]}$

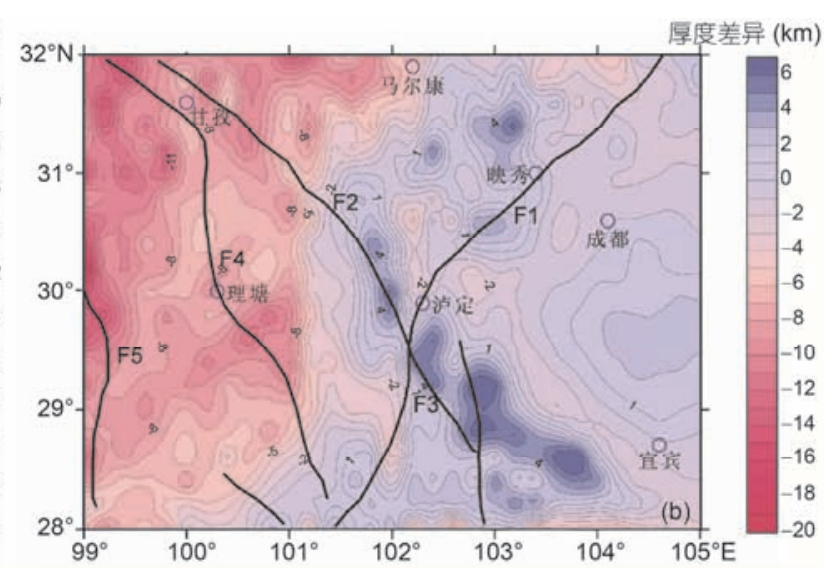

Figure 2 Distribution of theoretical isostatic crustal thickness (a) and isostatic crustal thickness difference $\Delta I$ (b) ${ }^{[96]}$ 


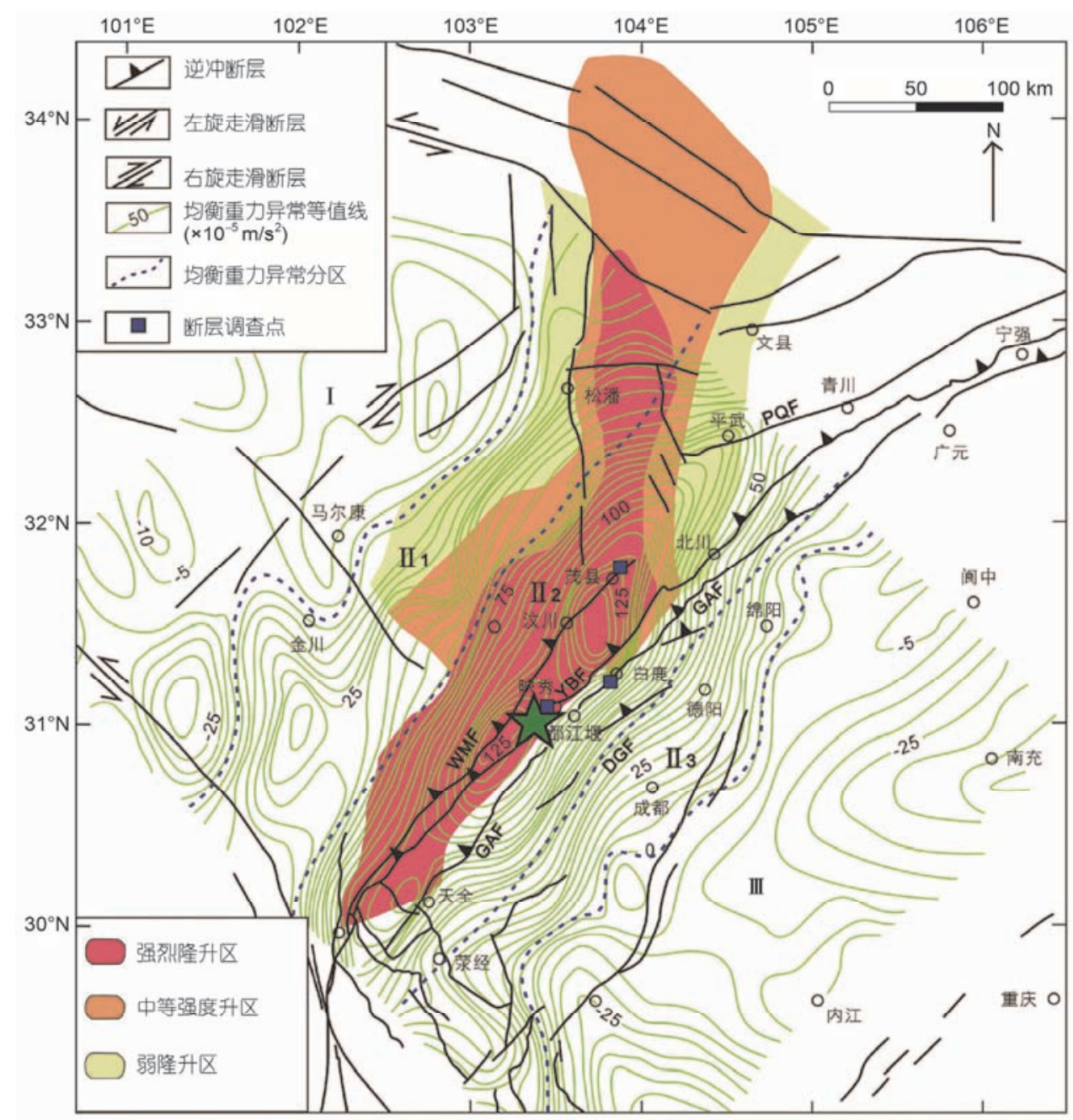

图 3 龙门山地区均衡重力异常分布图 ${ }^{[100]}$. 绿色细线为均衡重力异常等值线 $\left(\times 10^{-5} \mathrm{~m} / \mathrm{s}^{2}\right)$, 黑线为断裂, 绿色五角星为 2008 年汶川地震的震中. 蓝色虚线为均衡重力异常分区界限 ( I 为青藏高原东部弱负重力均衡异常区, II 1 为龙门山西侧弱正重力均衡异常区， II 2 为龙门山强正重力均 衡异常区, II 3 为四川盆地西部弱正重力均衡异常区，III为四川盆地中东部弱负重力均衡异常区). 彩色区为通过河床坡降反演所得隆起带分 区, 红色为强隆起区, 褐色为中等强度隆起区, 浅绿色为弱隆起区

Figure 3 Isostatic gravity anomaly and uplifting of Longmenshan and surrounding areas ${ }^{[100]}$. The green lines denote the contours of the isostatic gravity anomaly $\left(\times 10^{-5} \mathrm{~m} / \mathrm{s}^{2}\right)$. The black lines denote the faults. The green pentagram denote the epicenter of the 2008 Wenchuan-Yingxiu earthquake. The blue dotted lines denote the zoning boundaries of the isostatic gravity anomaly ( I indicates the weak negative anomaly at the Eastern Tibetan, II indicates weak positive anomaly at the western Longmenshan, II $_{2}$ indicates the strong positive anomaly at the Longmenshan, II ${ }_{3}$ indicates the weak positive anomaly at the western Sichuan basin, III indicates the weak negative anomaly at the mid-east region of the Sichuan basin). The color area denotes the uplifted zone derived from the inversion of river bed slopes. The red area denotes the highly uplifted zone, the brown area denotes the moderately uplifted zone, the light green area denotes the softly uplifted zone

场与周边的异常场差异; (2) 物质的重新分异、调整 改变了原有介质的密度均匀状态, 且向低速、低密度 转变; (3) 介质的密度变异导致了龙门山这一窄带区 间内高梯度的变化特征; (4) 该地带深部极为活动的 介质属性和结构变化造成了该地带重力场的高度不 均衡状态.

这里要略加说明的是, 凡是重力场高度的不均
衡地带, 却往往为深部壳、幔物质强烈交换的地带, 亦同时为强烈地震和大地震容易发生的危险地带(图 2和3), 如喜马拉雅造山带、东西构造结、川滇地带、 龙门山地带, 青藏高原北缘与塔里木盆地的相接地 域等均为重力场的高梯度变化带、重力场的高度不均 衡地带, 同时亦为现今陆内造山带、大型构造活动带 和强烈地震与大地震的发生地带. 这便充分表明, 一 
系列地带的地表构造和地震震中分布的确呈现出其 与地表局部现象的相关, 而深部物质与能量的交换 则为其本质 ${ }^{[88]}$.

\section{2 龙门山断裂系地带壳、幔精细结构与其 突变的深层过程}

青藏高原东北缘和川西高原地带构造活动, 强 烈地震频频发生, 故在这一地域曾做过多种地球物 理探测, 包括高精度人工源深部地震探测、天然地震 宽频带台网观测以及地球物理场和精细结构的研究, 取得了一系列的结果, 但却存在着相对峙理解或矛 盾. 尽管各有各的解释, 但不可回避的是数据本身和 方法上是存在差异的. 为此对多种结果在认识上必 须以观测精度和分辨率为核心, 以达厘定其物质属 性和结构, 但对逼近认识来说, 权重当必亦异.

\section{1 电性结构与 $\mathrm{S}$ 波速度结构概况}

电性结构和天然地震观测反演 $\mathrm{S}$ 波速度结构均受 到方法本身的约束和数据及精度的限制, 只能给出轮 廓性的结构分布状态, 且难以给出异常分布的下界.

(i ) 电性结构. 龙门山与其相邻地域的电性结 构给出了壳、幔结构电阻率轮廓 ${ }^{[29,30,80,103 ~ 111]}$. 在同 一带域内的图像中, 不论是电阻率分层、层厚、形态 等亦不尽相同 ${ }^{[30,38,43,110,112 ~ 114]}$. 但也都尖灭于四川盆 地与松潘-甘孜块体之间的龙门山地带. 尽管该区的 电性结构存在明显的分区性特点, 但仍难以从其图 像中给出量化的下地壳流判据.

航空磁测等值线分布形态表明: 松潘、甘孜、四 川盆地与龙门山断裂系间的分区性, 且龙门山断裂 系地带乃属低磁异常区 ${ }^{[115]}$, 此乃深部物质在重新分 异、调整过程中热效应所致.

(ii) 天然地震观测与 $\mathrm{S}$ 波速度结构. 在龙门山 及其相邻地域曾做过大量的不同方法反演的壳、幔结 构 ${ }^{[28,39,53,81,116 ~ 119]}$ 分析和研究, 但因天然地震的体波 与面波在用于反演壳、幔结构时是利用远程或较远程 (相对人工地震而言) 传播的地震波动信息, 在它到达 地震观测台站下方时包含了远程或较远程所经介质 和构造响应的信息. 由于震源函数未知、时间服务精 度低、确定震中位置等一系列误差的影响, 尽管用相 比值的办法可以在一定程度上消除路径、时间服务和 源函数的影响. 但其射线所经路程的介质、构造响应 在抵达台站下方的震相中却是不可能剔除的, 更为
重要的是仅利用了由高速到低速介质传播的上行波, 这便决定了天然地震信息的反演难以给出精细的速 度结构, 亦难以厘定分层的下界. 但在宏观属性和结 构, 特别是区域性三维 $\mathrm{S}$ 波速度结构研究中, 亦有其 优于二维人工源地震深部探测之点, 即相对经济, 不 会造成地面的破坏，且可以获得面上的结果.

基于地震瑞利面波存在着频散现象，而不同周期 面波的相速度对深度的反映是不同的. 利用程函方程 的面波成像方法，所得对应周期空间慢度场的分布， 可以得到与台站间距相当的分辨率 ${ }^{[78,120 ~ 123]}$, 并取得 了很好的成像结果 ${ }^{[124]}$. 采用670套宽频带流动地震 台站观测所得青藏高原东北缘12 60 s的不同周期相 速度对深度的响应是十分重要的 ${ }^{[125]}$. 例如 $12 \mathrm{~s}$ 的瑞 利面波相速度仅对8 18 $\mathrm{km}$ 深度的 $\mathrm{S}$ 波速度比较敏感, 即反映的是上地壳的速度变化, 周期 $16 \mathrm{~s}$ 的瑞利波相 速度对15 25 km深度的 $S$ 波速度比较敏感, 即主要反 映上地壳下部和中地壳上部的速度变化; 20 25 s 的 瑞利波相速度对 20 40 km深的S波速度比较敏感，即 主要反映中地壳的速度变化; 周期为 32 40 $\mathrm{s}$ 的瑞利 波相速度对30 70 km深度的 S波速度比较敏感; 周期 50 60 s的瑞利波相速度对60 70 km深度的 $\mathrm{S}$ 波速度 比较敏感, 即主要反映下地壳及上地幔顶部的速度 变化.

十分重要的结果是, 青藏高原及其东北缘地带 不存在下地壳流. 这一结果展示了与以往一些低分 辨结果难以取得的认识 ${ }^{[26,31,41,126 ~ 132]}$. 对青藏高原本 体而言, 在羊卓雍湖、帕母湖、羊八井一带存在局部 低S波速度或弱反射区，但却不等于存在或在整体上 均存在下地壳流.

天然地震面波频散、层析成像、接收函数、背景 噪声等方法在川滇地带已做了大量工作, 所得 $S$ 波成 像的图像差异较大, 难以划定层序及块体分层的较 准确范围, 亦难给出较细的分层和分块及其界带. 基 本上可近于达到的共识点为在龙门山地带上地壳低 速物质终止, 其宏观界带在龙门山陡断裂面处, $M_{\mathrm{S}} 8.0$ 大地震两侧介质属性和结构均产生突 变 ${ }^{[41,116,130,133]}$.

\section{2 龙门山地带高精度人工源地震探测和売、幔 精细结构与突变}

在该区曾进行过一系列精度不一的、长度不一的 人工源壳、幔结构探测剖面 ${ }^{[55,131]}$, 但却均难以给出普 
遍的认识. 然而有 4 条较长, 观测精度较高, 并给出 精细结构的剖面(其中有3条剖面位置是基本重合的). 它们是竹巴龙-龙门山-资中剖面 $\left(\mathrm{AA}^{\prime}\right)^{[117]}$ 、阿坝-理县双流剖面 $\left(\mathrm{BB}^{\prime}\right)^{[40]}$ 、龙门山及其南北相邻地带剖面 $\left(\mathrm{CC}^{\prime}\right)^{[42]}$ 、龙日坝-汶川-龙泉山剖面 $\left(\mathrm{DD}^{\prime}\right)^{[54]}$. 这4条剖 面的位置显示于图4. 后3条剖面 $\left(\mathrm{BB}^{\prime}, \mathrm{CC}^{\prime}, \mathrm{DD}^{\prime}\right)$ 的位 置是基本相同的. 从青藏高原东北缘到四川盆地地 域地表与深部地壳结构均变化强烈, 地壳厚度的垂 直变化幅度竟可达15 20 km, 而地表地形起伏差达 $3500 \pm 500 \mathrm{~m}$, 故在地形上、地表构造和地壳与上地幔 结构上均呈现出明显的反差, 即突变. 那么为什么汶 川-映秀 $M_{\mathrm{S}} 8.0$ 大地震就发生在这里呢?

(i ) 竹巴龙-龙门山-资中剖面 $\left(\mathrm{AA}^{\prime}\right)$ 壳、幔精细 结构. 通过人工源地震高精度剖面观测, 巴塘-理塘 -龙门山断裂系-资中壳、幔结构的精细刻化可求得其 壳、幔结构的异常变化.

首先, 四川盆地的壳、幔速度结构特征较为明显. 扬子克拉通主要由四川盆地及其西北缘构成. 在盆 地内部, 中、新生代沉积建造较厚 $(6 \mathrm{~km})$, 速度低 $(3.90 \mathrm{~km} / \mathrm{s})$; 上地壳相对较薄, 约 $12 \mathrm{~km}$; 中地壳厚度 $14 \mathrm{~km}$, 速度为 $6.33 \mathrm{~km} / \mathrm{s}$; 下地壳厚 $17 \mathrm{~km}$ 左右, 速度

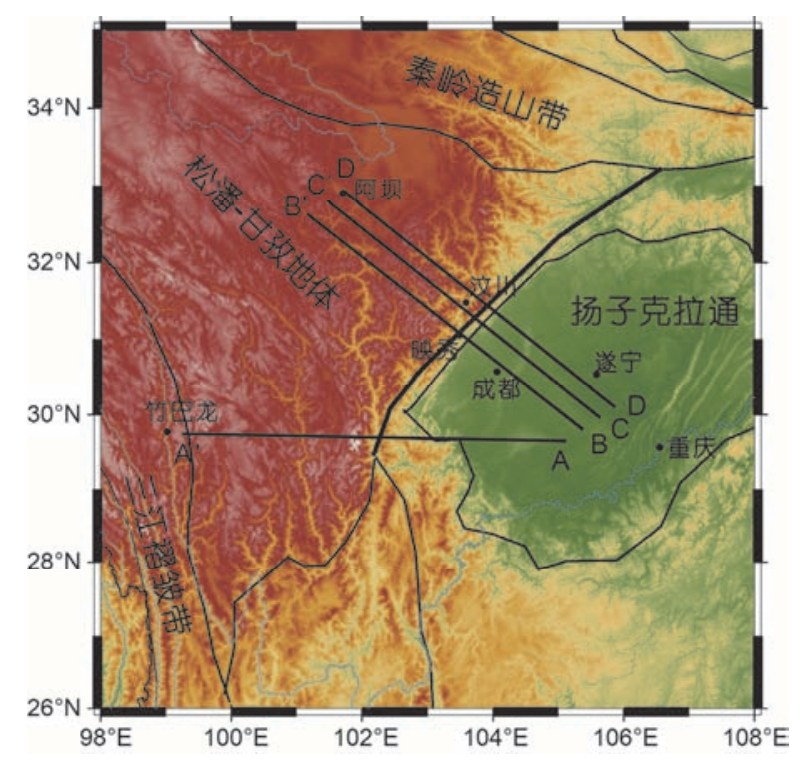

图 4 人工源地震剖面位置示意图. $\mathrm{AA}^{\prime}$, 竹巴龙-龙门山-资中剖面; $\mathrm{BB}^{\prime}$, 阿坝-理县-双流剖面; $\mathrm{CC}^{\prime}$, 阿坝-茂县-遂宁剖面; $\mathrm{DD}^{\prime}$, 阿坝-龙 门山-龙泉山剖面

Figure 4 Locations of the artificial seismic profiles. AA', Zhubalong-Longmenshan-Zizhong profile; $\mathrm{BB}^{\prime}$, Aba-Lixian-Shuangliu profile; $\mathrm{CC}^{\prime}$, Aba-Maoxian-Suining profile; $\mathrm{DD}^{\prime}$, Aba-LongmenshanLongquanshan profile
为 $6.90 \mathrm{~km} / \mathrm{s}$; 扬子克拉通的地壳厚度为 $40 \mathrm{~km}$ 左右, 平均速度为6.26 6.30 km/s, 地幔顶层速度为 $8.1 \sim 8.2$ $\mathrm{km} / \mathrm{s}$ (图5).

其次, 龙门山地带的壳、幔结构特征表现异常. 松潘-甘孜陆块与扬子克拉通之间所夹龙门山造山带 是地壳速度结构的强烈变异地带. 松潘-甘孜陆块区 的Moho界面深度为 $60 \sim 65 \mathrm{~km}$, 龙门山断裂系处为 50 $\mathrm{km}$ 左右, 错动幅度为 12 20 km, 四川盆地Moho界面 相对于龙门山断裂系西北侧明显抬升, 错动幅度近 $10 \mathrm{~km}$. 在龙门山断裂带上地幔顶部的速度较低, 为 $7.7 \pm 0.1 \mathrm{~km} / \mathrm{s}$, 说明龙门山断裂系下面的深部物质尚 在分异、调整和运移. 龙门山断裂系的断层面在总体 上向西北方向倾斜，即浅部角度陡，穿过上地壳后则 逐缓，但其各条断裂向西北方向的倾角均不相同.

最后，竹巴龙-龙门山-资中剖面下方的壳、幔结 构在龙门山地带存在突变状况. 由竹巴龙-鲜水河之 间壳、幔结构变化平稳, 而在鲜水河断裂与龙门山断 裂系之间却是一个突变的地带; 地壳厚度由 $65 \mathrm{~km}$ 变 浅为 $50 \mathrm{~km}$, 地壳低速层厚度为 $6 \sim 8 \mathrm{~km}$, 速度为 5.8 $\mathrm{km} / \mathrm{s}$, 且在此尖灭, 上地幔顶层Pn速度亦由 $7.8 \mathrm{~km} / \mathrm{s}$ 降为 $7.7 \mathrm{~km} / \mathrm{s}$.

该剖面的速度结构亦表明, 龙门山断裂系乃为 与四川盆地的“隔离带”, 且以上地壳低速层为上滑 移面, 地幔软流层顶部为下滑移面, 在地壳与上地幔 盖层即岩石圈物质在四川盆地阻隔下同步运移, 而 不是下地壳流动 ${ }^{[27]}$. 导致这次大地震的发生, 数值 模拟也证实了青藏高原下地壳不可能整体流动的结 论 $^{[135,136]}$.

(ii) 阿坝-理县-双流高精度壳、幔结构.上一 剖面, 即竹巴龙-龙门山-资中剖面为东西向, 即由甘 孜断裂带、鲜水河断裂带向东进人四川盆地, 并切过 龙门山断裂系, 而该剖面则为近南北方向 $\left(\mathrm{BB}^{\prime}\right)$, 由 甘孜-理塘块体向南穿过龙门山断裂系后进人四川盆 地的剖面(图S2).

松潘-甘孜块体的地壳变化基本平稳, 上地壳中 存在一低速层, 厚 $6 \sim 8 \mathrm{~km}$, 速度为 $6.0 \pm 0.1 \mathrm{~km} / \mathrm{s}$, 向 南延伸抵理县、都江堰之后尖灭, 整个壳、幔结构均 向上抬升 $10 \mathrm{~km}$ 左右, 整体地壳厚度为 $60 \mathrm{~km}$ 左右.

龙门山地带不仅地壳由深变浅, 即抬升 $10 \mathrm{~km}$ 左 右, 而且地表地形变化为 $3500 \pm 500 \mathrm{~m}$, 地壳厚度为 $50 \mathrm{~km}$ 左右, 在这一地带地壳各层的速度则减小 $0.2 \pm 0.05 \mathrm{~km} / \mathrm{s}$, 形成了这一地带特异的起伏和速度的 


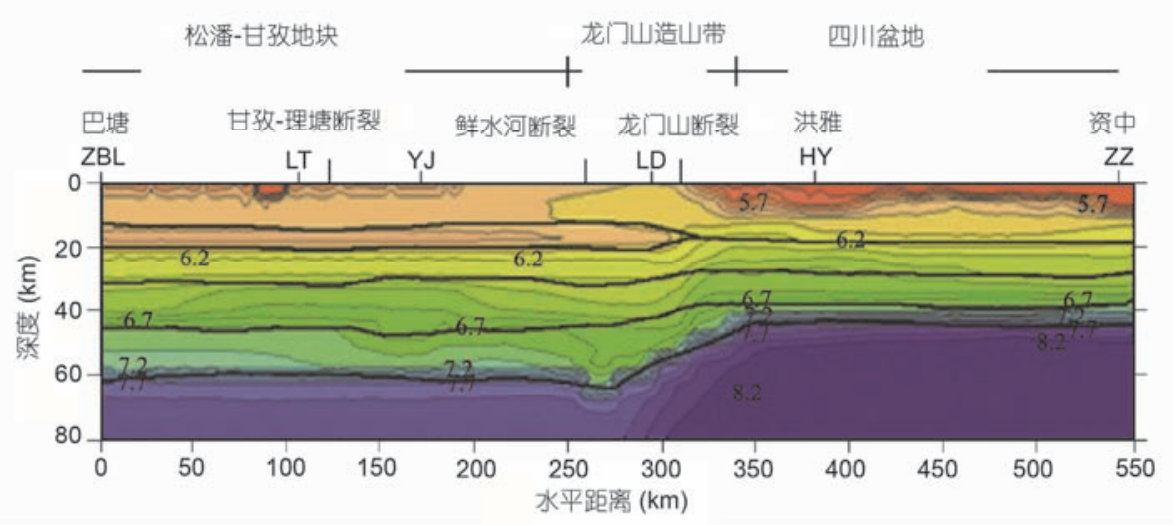

图 5 竹巴龙-龙门山断裂系-资中地壳与上地幔结构剖面图 ${ }^{[134]}$

Figure 5 Structure of crust and upper mantle along the Songpan-Ganzi-Longmenshan-Zizhong ${ }^{[134]}$

变化.

显见，由松潘-甘孜块体向南穿越龙门山断裂系 后进人四川盆地的壳、幔结构变异基本相同, 龙门山 地带亦乃强烈变化地带.

由震源而产生的绕射波(或称衍射波)及其叠加 效应等, 然而在未能进行速度滤波子波场分离的情 况下一并当作反射波处理, 势必会导致局部构造畸 变和沿断裂系低速小块体的出现, 应当确切地说, 这 种小区域点的异常现象, 当今的观测与反演是难以 分辨的. 因此, 这一地带的整体变异是属实的, 而龙 门山地带不论是断裂位置、介质属性, 还是速度分层 结构的求取及变异, 及其微小的异常块体均难以确 认. 近地表3 条西倾的断裂带位置可另作调整, 即如 图S2所示, 显然图 S2中北部3条断裂并列存在, 地表 3条断裂向下收玫、汇聚于大地震发生的地方却是共 识的(图S2).

(iii) 龙日坝-汶川-龙泉山壳、幔结构剖面( $\left.\mathrm{DD}^{\prime}\right)$. 这条剖面 ${ }^{[54]}$ 与阿坝-茂县-遂宁剖面 $\left(\mathrm{CC}^{\prime}\right)^{[137]}$ 人工源 壳、幔精细结构探测剖面位置分布和壳、幔速度结构 (图6和7)在整体结构框架上相近, 但却存在局部差 异. 两条剖面即存在相同部分, 也存在不同之处.

二者的结构与属性相近：松潘-甘孜地区、四川 盆地地区与龙门山地带整体壳、幔介质结构基本一 致; 龙门山地带的地壳厚度较其南北两侧的变化幅 度各自为 $10 \mathrm{~km}$ 左右, 合计变化幅度可达 15 20 km; 汶川、映秀、江岫断裂带所辖地带为北部松潘-甘孜 块体沿龙门山断裂带陡峭断层面的逆冲地带.

二者也存在明显差异: 不存在5 10 km处的地壳 低速层 (嘉世旭 ${ }^{[42]}$ 结果中认为存在), 从图6来看, 应
存在; 中、下地壳为层速度连续有序变化的介质, 不 存在下地壳流 ${ }^{[54]}$; 壳、幔结构细节差异明显, 但尚难 确定.

对3条位置相近的剖面内涵进行重新认识. 此处 的3条剖面分别指阿坝-理县-双流剖面、龙日坝-汶川龙泉山剖面和阿坝-茂县-遂宁剖面. 图6分层结构略 为单一, 而且图7又过于复杂. 由图6可见, 实际上其 中 $\mathrm{C}_{2}$ 与 $\mathrm{C}_{4}$ 之间介质在整体上速度偏低, 即应注明为 $5.8 \sim 6.0 \mathrm{~km} / \mathrm{s}$ 更为合理, 其上界 $\mathrm{C}_{2}$ 以上介质总体上平 均速度为 $6.1 \sim 6.2 \mathrm{~km} / \mathrm{s}$ 较为适宜, 而其下界介质应为 6.4 6.5 km/s. 按这样的分层速度结构则 $\mathrm{C}_{2}$ 与 $\mathrm{C}_{3}$ 之间 应为上地壳中的低速层，厚度为 $6 \sim 8 \mathrm{~km}$, 即与前述 图5和6基本一致. 汶川、北川、江油地带为龙门山 断裂系的陡峭断层面, 且松潘-甘孜壳、幔物质沿其 逆冲.

图7分层结构过细, 且能划出 1 2 $\mathrm{km}$ 厚, 或3 $5 \mathrm{~km}$ 厚, 长30 40 km的异常体确应慎之又慎. 因为 当今地壳与上地幔速度结构探测方法的精度与分辨 率达不到这样的尺度. 而十分重要的是在龙门山断 裂系地域性特点清晰表明: 爆炸点越密集, 则由断层 面产生的侧面波，断层棱边作为次生震源激发的绕 射波(衍射波)集聚叠加，完全改变了介质中反射波场 的面貌; 而在反演时又没有进行波场分离和其非有 效波的剔除, 且均作为反射波处理, 当必使得这一地 带的介质属性和结构受到一定程度的改造并导致龙 门山造山带地域介质分层速度结构的变异.

修改补充: 龙门山逆冲断裂系位置. 图6和7中已 标出龙门山大型逆冲断裂带的垂直准确位置, 应为 图中新划分的断层面(黑色)(图7). 在上述2条剖面中 


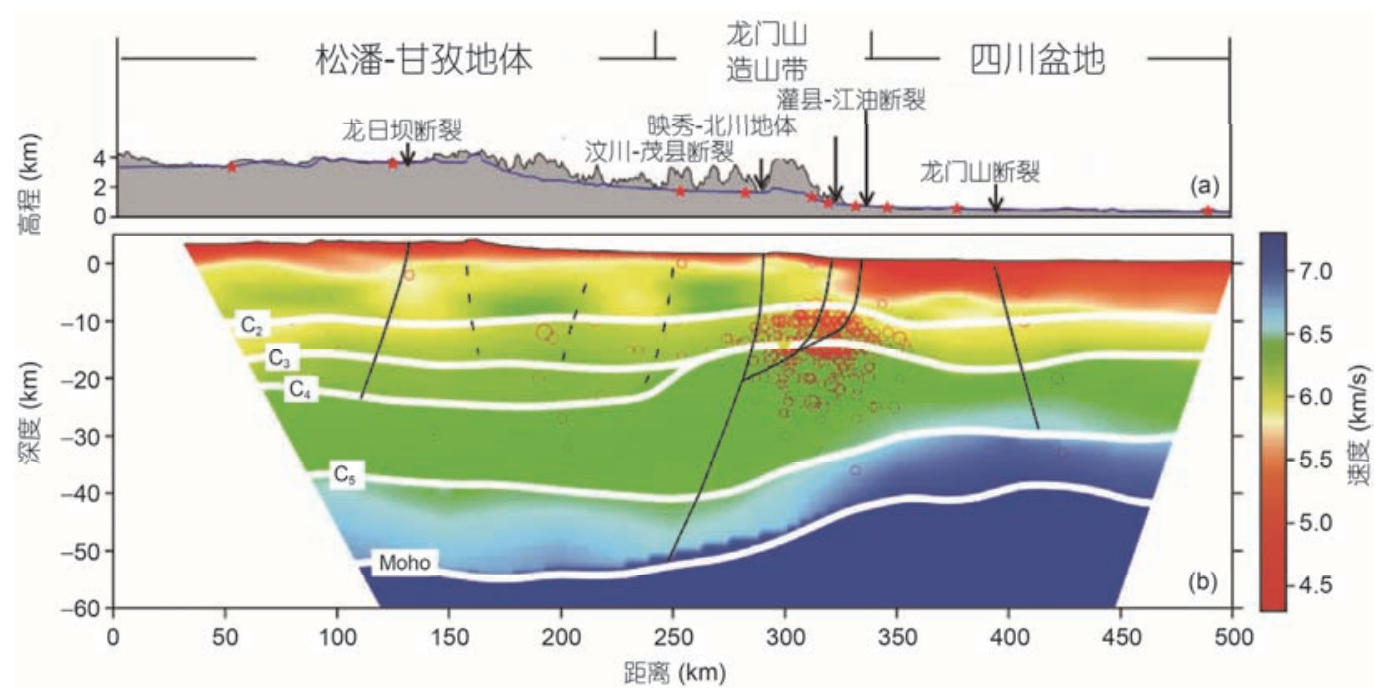

图 6 龙日坝-汶川-龙泉山地带地壳二维速度结构与逆冲断层的位置分布图(据张新彦等人 ${ }^{[54}$ 修改补充). (a) 高程图及各断裂分布, 其中蓝线为 检波器高程, 红色五角星为炮点位置. (b) 速度模型

Figure 6 2D whole crustal velocity model (modified from Zhang et al. ${ }^{[54]}$ ). (a) Elevation and faults along the profile, with the blue line indicating elevation of receivers and red stars as shots; (b) the velocity model

$\left(\mathrm{CC}^{\prime}\right.$ 与 $\left.\mathrm{DD}^{\prime}\right)$, 地壳与上地幔顶部速度结构的整体响 应基本上是保持一致的, 而在具体细节上有差异; 速 度差异为 $0.05 \sim 0.1 \mathrm{~km} / \mathrm{s}$, 深度与厚度差异为 $\pm 2 \mathrm{~km}$. 在4条剖面 $\left(\mathrm{AA}^{\prime}, \mathrm{BB}^{\prime}, \mathrm{CC}^{\prime}\right.$ 与 $\left.\mathrm{DD}^{\prime}\right)$ 中地壳、上地幔顶部 各层总体变化一致的前提下, 考虑到权重因素给出 了川西高原、四川盆地、龙门山地带的各项参数变化 (表1). 从介质属性和结构变异可见, 川西高原的松 潘-甘孜地带地壳与上地幔相对于四川盆地较软, 四 川盆地为一稳定的坚实陆核, 而龙门山地带不论是 各层的速度值、厚度值、深度值均为一特异的地带, 而有别于其西北与东南两侧所得结果. 应当确切地 说, 在穿越龙门山断裂系的剖面中, 应以竹巴龙-龙 门山-资中剖面 $\left(\mathrm{AA}^{\prime}\right)$ 和阿坝-理县-双流剖面 $\left(\mathrm{BB}^{\prime}\right)$ 为基 本本底剖面.

(iv) 龙门山地带壳、幔精细结构的模型. 通过 上述4条人工源高精度剖面 $\left(\mathrm{AA}^{\prime}, \mathrm{BB}^{\prime}, \mathrm{CC}^{\prime}\right.$ 与 $\left.\mathrm{DD}^{\prime}\right)$ 观 测, 高分辨率的数据采集和壳、幔精细结构的剖划, 结果一致表明, 这里是松潘-甘孜与四川盆地西缘之 间的显著界域, 是地壳结构和地形的突变地带. 表 1 展示了龙门山断裂系与其相邻地域的壳、幔结构平均 参数特征.

基于表1所给出的 3 个地层的精细壳、幔结构数据 与它们的差异、特点及分布形态, 可以建立起一个汶 川-映秀 $M_{\mathrm{S}} 8.0$ 大地震发生的二维概念模型 (图 8). 该 图清晰地表征出龙门山断裂系南北两侧的分层和速
度结构的特异变化特征，同时表征着低速层的尖灭， 龙门山断裂系乃北部松潘-甘孜块体相对较软的壳、 幔介质在四川盆地较硬的壳、幔介质阻隔下沿龙门山 断裂系主断层面向上逆冲图像. 这一界带即为龙门 山陡峭的断裂系.

\section{3 汶川-映秀 $M_{\mathrm{S}} 8.0$ 大地震的发震断层: 震 源深处汇聚断裂带}

在发震断层问题上地球物理 界 $[24,27,40,42,43,45 \sim 47,49,53,54,62,64,83,89,92,101,103,126,130,134,138 \sim 143]$ 和地质界 ${ }^{[3,4,7,9,11,13,16,20,144 \sim 148]}$ 是有分歧的, 后者认为 是地表构造活动断裂所致，而前者从地震震源是一 个体积理念出发, 则证明了其为震源深处物质运动 与破裂的深层过程与动力响应所致.

\section{1 浅表过程不能厘定大地震的发生}

(i) 地表GPS测量不能表征深层过程. 强烈地 震或大地震的发生是震源深处介质在力系作用下重新 分异、调整和运移的结果. 在鲜水河断裂带GPS速度 场测量为 8 10 mm/a, 安宁河-侧本合-小江断裂带为 $5 \sim 6 \mathrm{~mm} / \mathrm{a}$, 而龙门山断裂系上仅为 $1 \sim 3 \mathrm{~mm} / \mathrm{a}^{[13,149 \sim 154]}$. 据此理当在前两条断裂带上发生强烈地震或大地震 的概率最大, 且 $6 \leqslant M_{\mathrm{S}} \leqslant 8$ 的地方频频发生. 可是在 这两条断裂带上却从未发生过 $M_{\mathrm{S}} \geqslant 8$ 的地震, 而就在 这相对变异较小的龙门山地带, 即从未发生过 $M_{\mathrm{S}} \geqslant 6$ 


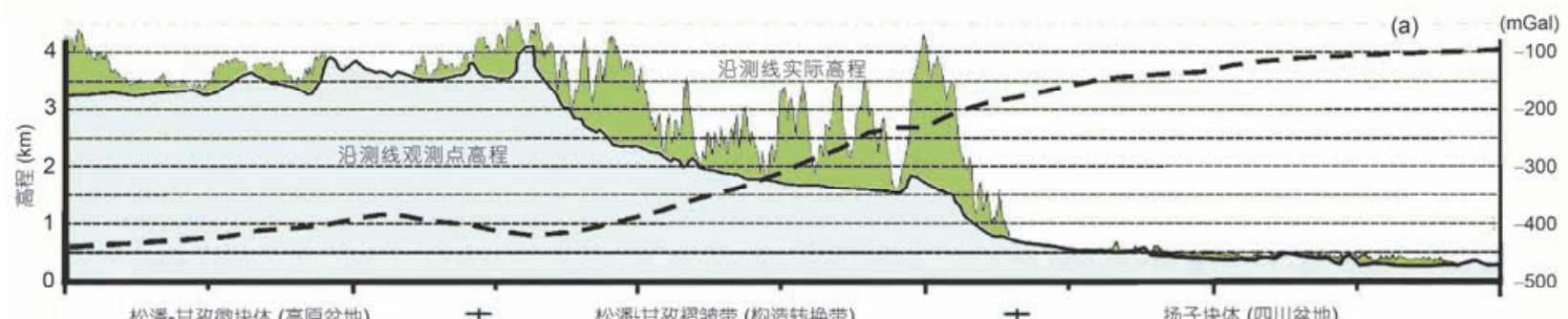

松潘-甘孜微块体 (音原盆地) +
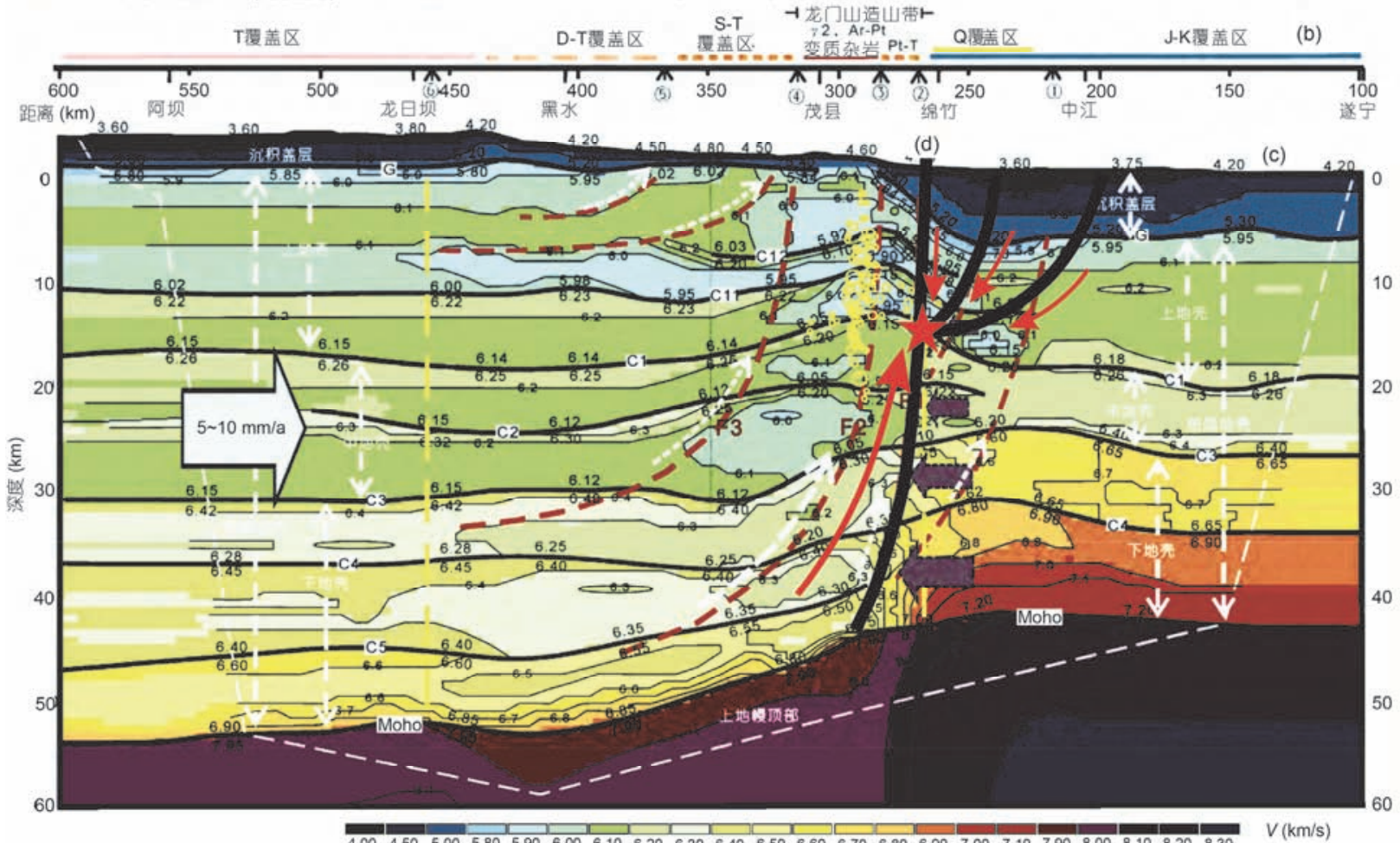

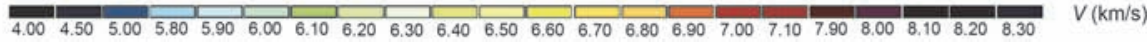

图 7 阿坝-茂县-遂宁剖面 $\left(\mathrm{CC}^{\prime}\right)$ 地壳结构与 5.12 汶川大地震(据嘉世旭等人 ${ }^{[42]}$ 修改补充). (a) 沿测线接收点高程、实际高程和布格重力值; (b) 构造单元及地表岩性分布; (c) 深地震测深地壳速度结构与构造模型; (d) 重新厘定的断层位置(黑色粗线). (1) 巴中-龙泉山断裂; (2) 江油-都 江堰断裂; (3) 北川-映秀断裂; (4) 茂汶断裂; (5) 东门沟断裂; (6) 龙日坝断裂; (7) 红色圆点为 $M_{\mathrm{S}} 8.0$ 大地震

Figure 7 Crustal structure of the north and south sides of the Aba-Maoxian-Suining profile $\left(\mathrm{CC}^{\prime}\right)$ and the 5.12 Wenchuan earthquake (modified from Jia et al. ${ }^{[42]}$ ). (a) Elevation of receivers, topography and Bouguer gravity; (b) tectonics division and rock distribution; (c) crustal velocity structure and tectonic model derived by the deep seismic sounding; (d) relocated fault position (the black thick line). (1) Bazhong-Longquanshan fault; (2) Jiangyou-Dujiangyan fault; (3) Beichuan-Yingxiu fault; (4) Maowen fault; (5) Dongmengou fault; (6) Longriba fault; (7) $M_{\mathrm{S}} 8.0$ Wenchuan earthquake (the red star)

表 1 龙门山断裂带与其相邻地域的壳、幔结构平均参数特征表

Table 1 The average parameter table of the crust and mantle structure beneath the Longmenshan Fault system and its surrounding areas

\begin{tabular}{|c|c|c|c|}
\hline 壳、幔物质参量 & 松潘-甘孜地带 & 龙门山断裂系地带 & 四川盆地地带 \\
\hline 地形高程(m) & $3500 \pm 500$ & $1500 \sim 4300$ & $500 \pm 50$ \\
\hline 地壳厚度(km) & $60 \pm 5$ & $50 \pm 5$ & $40 \pm 2$ \\
\hline 地壳平均速度 $(\mathrm{km} / \mathrm{s})$ & $6.2 \pm 0.1$ & 难厘定 & $6.30 \pm 0.1$ \\
\hline 地壳低速层深度 $(\mathrm{km})$ & $20 \pm 5$ & 尖灭 & 无 \\
\hline 地壳低速层速度(km/s) & $5.9 \pm 0.1$ & 尖灭 & 无 \\
\hline 地壳低速层厚度(km) & $8 \pm 2$ & 尖灭 & 无 \\
\hline 上地幔盖层速度 $(\mathrm{km} / \mathrm{s})$ & $7.8 \pm 0.1$ & $7.7 \pm 0.1$ & $8.15 \pm 0.05$ \\
\hline 物质运动状态 & 较强烈 & 复杂, 极强烈 & 稳定 \\
\hline 上地幔软流圈顶部深部 $(\mathrm{km})$ & $110 \pm 10$ & $100 \pm 10$ & $90 \pm 10$ \\
\hline
\end{tabular}




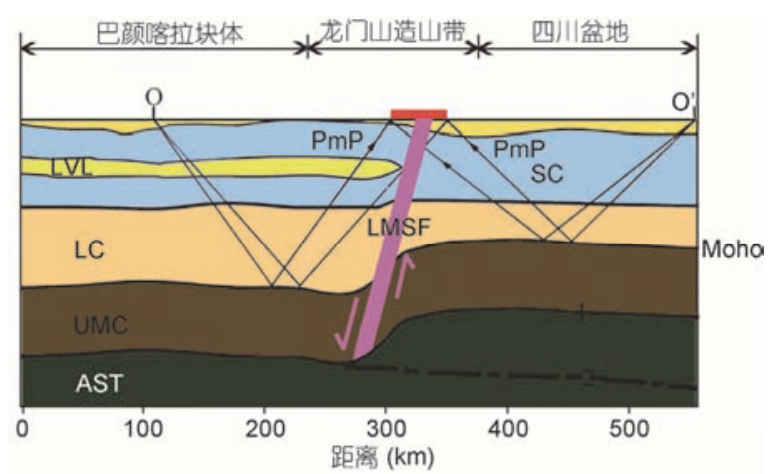

图 8 巴颜喀拉块体-龙门山造山带-四川盆地地带地壳与上地幔平均 结构概念性模型示意图. $\mathrm{O}, \mathrm{O}^{\prime}$, 震源点; SC, 上地壳; LVL, 地壳低速 层; LC, 下地壳; Moho, 地壳底界面; UMC, 上地幔盖层; LMSF, 龙 门山断裂带; AST, 软流圈; 1, 2, 在四川盆地软流圈深部的两种方案 (本作者认为是“ “1”)

Figure 8 Schematic diagram for average structure of crust and upper mantle along the profile from Bayan Har Block-Longmenshan Orogenic-Sichuan Basin. O, O', source points; SC, upper crust; LVL, low velocity layer of crust; LC, lower crust; UMC, covering strata of upper mantle; LMSF, Longmenshan fault; ASF, asthenosphere; proposal 1, 2, deep of asthenosphere by two program in Sichuan basin (we believe proposal 1 is right)

地震的地带却发生了 $M_{\mathrm{S}} 8$ 的大地震. 地震发生后出现 了两种解释: (1) GPS测量值大处可能会发生强烈地 震或大地震, 而在GPS测量值小处, 亦会发生强烈地 震或大地震, 可是震前龙门山断裂系所辖地带未见 明显变形, 即称GPS速度场最小处为闭锁. 那么GPS 测量值为何数值时才不会或不可能发生强烈地震或 大地震? (2) 而另一种认识则认为 GPS速度场测量值 可以表征某些近地表的活动现象, 但却不能说明它 是震源深处深层动力过程在地表的直接反响. 因为 “闭锁”在物理上未能给出厘定, 即这里的地震是活 动的呢? 还是区域稳定的呢? 又为什么?

(ii) 地表龙门山断裂系本身不是发震断层. 汶 川-映秀 $M_{\mathrm{S}} 8.0$ 大地震发生后, 基于 $M_{\mathrm{S}} 8.0$ 主震和 70000 多次余震在地表震中位置的分布提出, 汶川-茂县逆 断层、映秀-北川逆断层、彭县-灌显断裂和龙门山山 前断裂是发震断裂, 并将主震和一系列强余震的发 生均归属为地表龙门山断裂系中的某一条断裂带, 如 $M_{\mathrm{S}} 8.0$ 主震发生在龙门山断裂系中的映秀-北川断 裂上 ${ }^{[12,13,20,155,156]}$, 把一些强余震归属于汶川-茂县断 裂和新县-灌县断裂等 ${ }^{[17,157,158]}$. 这一系列在地表的震 中位置乃是震源深处地震发生后, 通过由震源到地 表不均匀、各向异性介质和错综断裂及破碎带后在地 表的近似位置分布, 即是一种在地表的展布. 他们不
是由震源到地表并扣除介质响应的垂直投影位置, 何况在理想情况下确定震中位置的误差为 $10 \pm 5 \mathrm{~km}$ 呢!

显然, 这地表的一系列断裂发不了震, 特别是强 烈地震和大地震. 也就是说, 浅源地震、中源地震, 或是深源地震均不可能是地表的某一条断裂带伸展 震源深处所致, 即便是浅源地震的断裂系亦有可能 深抵一定深处, 但地震的发生并非某一条断裂所及, 而应是其断裂系收玫到某一深度的汇聚. 因为地震 的震源不是一个点, 也不是一条线, 而是一个体积, 即震源体积.

\section{2 汶川-映秀 $M_{\mathrm{S}} 8.0$ 大地震的发震断裂是上地壳 深部汇聚断裂带的证据}

证据之一，70000多次余震震源深度分布与主震 震源深度分布存在显著的一致性. 汶川-映秀 $M_{\mathrm{S}} 8.0$ 大 地震发生后, 又发生了 70000 多次余震, 其中包括 6.0 级左右的强余震在内, 经过对这些地震进行精细定 位后, 给出了大、小地震震源深度的分布范围. 统计 结果表明, 沿龙门山造山带地带的所有大、小地震的 震源深度均分布在5 20 km的深度范围内, 主体上为 10 20 km之间, 而其统计峰值为 $15 \pm 5 \mathrm{~km}^{[45]}$. 这与在 2008 年 $M_{\mathrm{S}} 8.0$ 大地震发生后给出的震源深部结果 ${ }^{[3,140]}$ 和2011年1月中国地震局数据中心等部门确定的震源 深度为 $15 \mathrm{~km}$ 左右的结论是极为一致的.

证据之二, 主震破裂响应与主震震源深度分布 相依. 基于汶川-映秀 $M_{\mathrm{S}} 8.0$ 大地震发生的物理理念, 震源深部介质在应力作用下开始破裂与变形, 称其 为微破裂, 待应力不断增强而驱使破裂不断扩展, 并 逐渐形成破裂链(二维)或破裂体积(三维), 当应力集 中并达到临界状态时, 震源深处介质的质点以地震 波动为载体向三维空间辐射, 最后突破上覆大质量 物质的压力而冲出地表, 大地震发生, 地表强烈破 坏 ${ }^{[46,47]}$.

这次大地震发生后, 对地震的破裂效应曾有不 少讨论 ${ }^{[49,138]}$. 共同的特点表明, 沿龙门山断裂系的 地壳深处, 即在震源深处和大量余震分布的地带, 并 在二维空间形成了一条强弱不均匀的破裂链(图S3), 且在主震 $M_{\mathrm{S}} 8.0$ 震源深处破裂强度最大, 并沿着这一 深度呈带状向两侧延伸.

证据之三, 精细壳、幔结构突变与大地震发生的 深层过程. 龙门山地带与两侧相比, Moho界面垂向 
减薄幅度达15 20 km, 低速层在此处尖灭, 且川西 高原松潘-甘孜块体的壳、幔结构沿龙门山断裂系陡 峭的断层面向上逆冲和壳、幔结构的概念性模型的样 式(图 $8, \mathrm{~S} 3$ 和 9 ) 阐明了 $M_{\mathrm{S}} 8.0$ 大地震发生的深层动力 过程.

\section{3 震源深处的汇聚断裂乃这次 $M_{\mathrm{S}} 8.0$ 大地震的 发震断裂带}

松潘-甘孜块体、龙门山造山带和扬子克拉通西 北缘正是地表地形高差变异十分显著的地带 (即 $3500 \pm 500 \mathrm{~m}$ ), 且龙门山断裂带的断层面十分陡峭, 这里的地壳厚度差亦可达15 20 $\mathrm{km}^{[27,46]}$. 这便表明, 要厘定汶川 $M_{\mathrm{S}} 8.0$ 大地震的发震断裂, 就必须去探索 其孕育、发生和发展的深部介质属性和构造环境极其 深层动力过程.

( i ) 龙门山造山带地域的受力作用特征. 由于 松潘-甘孜块体与四川盆地在龙门山断裂系地带相对 峙, 由浅人深均为一个介质属性和结构的强烈变化 地带. 同时龙门山断裂系又是在巴颜喀拉块体向东 南运移, 扬子克拉通向西北运移, 即为在东南、西北 两大块体强力挤压下的受力作用地带. 在长时间的 挤压作用下, 龙门山中南段近水平滑脱带宽达数十 公里, 且在16 21 km深处出现3个滑动量达6 7 $\mathrm{m}$ 的 破裂区, 深部低角度破裂向上转为高角度逆冲, 沿龙 门山断裂带以约 $55^{\circ}$, 乃至 $70^{\circ} \sim 80^{\circ}{ }^{[159]}$ 的倾角出露地 表 ${ }^{[160]}$, 汶川地震破裂的几何产状和滑移幅度表明龙 门山逆冲断裂带发育有大规模的近水平运动. 依据 汶川-映秀 $M_{\mathrm{S}} 8.0$ 大地震变形场的 GPS 和InSAR反演近 地表断层滑移结果表明, 在北川、青川地区存在滑移, 最大量为 $9 \mathrm{~m}$ (北川县城), 且集中在地壳内深为 $0 \sim$ $16 \mathrm{~m}$ 处 ${ }^{[161]}$. 为此, 由于挤压而驱动, 应力集中、深部 物质和能量必将进行着强烈的交换, 故龙门山地带 呈垂向隆升 ${ }^{[150]}$, 并促使这里形成了强烈地震“孕育”、 发生和发展的深部空间. 青藏高原东缘相对于四川盆 地的差异隆升, 对高倾角逆冲断裂的库仑力作用表明, 对龙门山逆冲断裂近地表的活动有促进作用. 这表明, 在龙门山断裂系地带挤压应力作用下确存在着水平向 滑动，同时亦存在着垂向的隆起.

(ii ) 龙门山地表断裂在震源深处的收玫. 龙门 山地表主要有 3 条断层, 它们共同组成了龙门山断裂 系. 这3条断层以不同的角度西倾, 并向震源深处收 玫, 而在深度为 $15 \pm 5 \mathrm{~km}$ 处汇聚形成了一条 NE向的 深部汇聚断裂带(图9(a)和(b)). 这条汇聚断裂带与深 度 $15 \pm 5 \mathrm{~km}$ 处的破裂链同步(图 $\mathrm{S} 3$ ), 与主震、强余震、 70000 多次小余震的震源深度分布 $(10 \sim 20 \mathrm{~km})$ 一 致 ${ }^{[27,45,46]}$.

(iii) 松潘-甘孜地壳与上地幔盖层沿龙门山断裂 系主断层面向上逆冲与 $M_{\mathrm{S}} 8.0$ 大地震的发生. 基于 地壳与地幔高精度速度结构的研究, 即 4 条穿越龙门 山断裂系地震剖面的属性和结构特性, 松潘-甘孜地 带的壳、幔结构相对于扬子克拉通地壳、幔结构较 “软”, 故在四川盆地强劲阻隔下, 上地壳低速层以下 的物质与上地幔盖层物质沿长时期挤压力系作用下 的龙门山断裂系的陡峭断层面向上逆冲, 且与由上 向下收敛的 3 条断裂共同形成的汇聚断裂带强烈碰 撞, 故导致了在震源深处 $15 \pm 5 \mathrm{~km}$ 位置发生了这次 $M_{\mathrm{S}} 8.0$ 大地震.

显然这条在 $15 \pm 5 \mathrm{~km}$ 深处的汇聚断裂带, 是不可 能与在地表所见龙门山断裂系中各条断裂带各自的 规模或宽度相比, 而是要比它们各条断裂带的规模 均要宽大的一个有限范围内的震源体. 由于这一在 震源深处汇聚的发震断裂带规模大, 且为一个震源 体积, 故才可能沿NE方向形成一条长达 $300 \mathrm{~km}$ 以上 的强烈破裂带. 该破裂带是以 $15 \pm 5 \mathrm{~km}$ 深度为中心的 震源区, 并证实了这一长近 $300 \mathrm{~km}$ 以上的汇聚断裂 带是以 $5 \mathrm{~km}$ 为半径, 走向 NE的柱状震源体(图S4).

因为这里发生的一系列地震, 包括主震 $\left(M_{\mathrm{S}} 8.0\right)$ 、 强余震 $\left(6 \leqslant M_{\mathrm{S}} \leqslant 6.8\right)$ 和 70000 多次小余震近似投影在 地表的震中位置呈现出一条宽约 $60 \mathrm{~km}, \mathrm{NE}$ 向长达 $300 \mathrm{~km}$ 以上的区带, 而且非集中在某一断裂上面(图 S5). 若依图 S5 中各条NW向剖面的震源深度分布, 亦表明, 这一系列地震的震源深度均分布在 $15 \pm 5 \mathrm{~km}$ 的深度范围内(图S6).

由于这里应力集中, 地震释放能量的强度最大、 也最多，且向纵向和横向辐射，故这条收敛于 $15 \pm$ $5 \mathrm{~km}$ 深处的剪切断裂带乃是汶川 $M_{\mathrm{S}} 8.0$ 大地震, 一系 列 $6 \leqslant M_{\mathrm{S}} \leqslant 6.8$ 之间的强余震和 70000 多次小余震的发 震断裂带(图S5), 即发生在地壳低速层上部的坚硬上 地壳介质中 ${ }^{[27,40,46,47,134,149]}$.

\section{4 汶川-映秀 $M_{\mathrm{S}} 8.0$ 大地震㝋育与发生的力 源机制}

在印度洋板块与欧亚板块近 $40 \mathrm{Ma}$ 以来长期的碰 撞、挤压作用下, 并在地中海-喜马拉雅-南亚世界强 


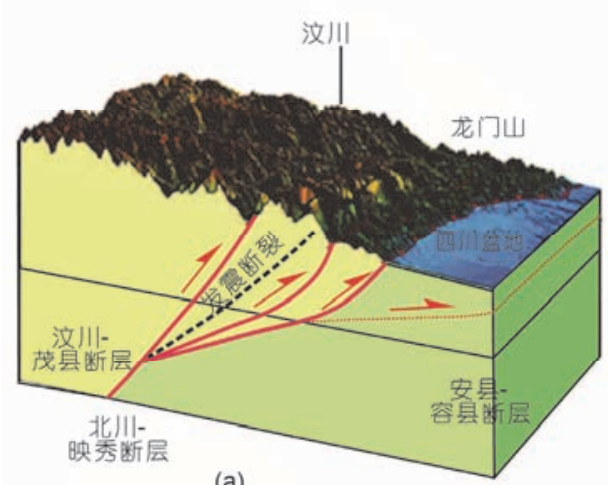

(a)

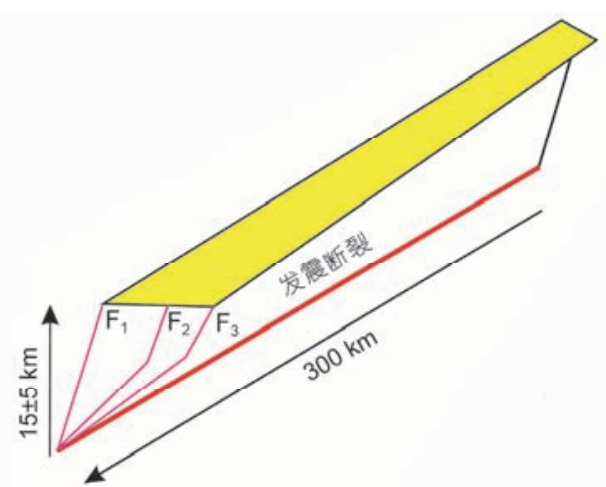

(b)

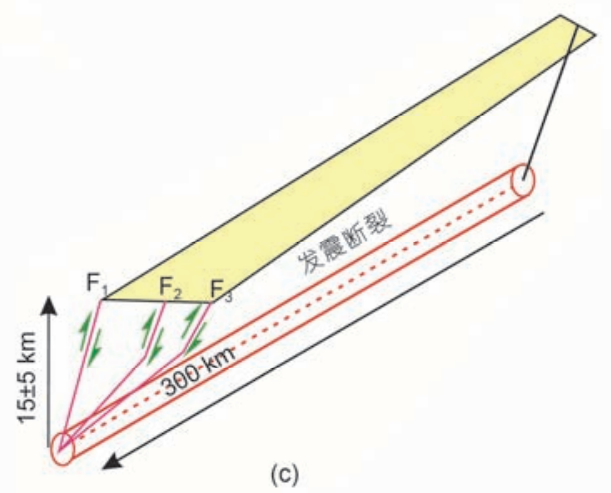

(c)

图 9 龙门山断裂系的各条断裂带西侧与在深部 $15 \pm 5 \mathrm{~km}$ 处汇聚和发震断裂带的示意图. (a) 断裂构造分布; (b) 深部断裂与发震断裂; (c) 发震 的柱状震源体

Figure 9 Sketch showing $15 \pm 5 \mathrm{~km}$ deep convergence and seismogenic columnar source of seismogenic fault. (a) Distribution of faults; (b) deep faults and seismogenic faults; (c) seismogenic columnar source

烈地震活动带的驱动下, 青藏高原整体隆升, 喜马拉 雅山系高高崛起 $(8848.43 \mathrm{~m})$ 和东西两个构造结的形 成及两大陆块边界的极大不稳定性, 共同造成了由 加德满都-雅鲁藏布江地域的重力极不均衡和深部物 质与能量的强烈变换. 沿此界带自 1505 年至今已发 生了 8 次 $M_{\mathrm{S}}>8.0$ 的大地震 ${ }^{[162 ~ 164]}$. 这是一个深部与浅 部、纵向与横向的耦合地域, 是深部物质在极不稳定 条件下物质与能量的强烈交换的地带, 是世界上两 大地震带中的重要组成部分.

\section{1 汶川-映秀 $M_{\mathrm{S}} 8.0$ 大地震是板内发生的大地震}

汶川-映秀 $M_{\mathrm{S}} 8.0$ 大地震的孕育、发展与发生在青 藏高原东南缘和喜马拉雅造山带地带的地震背景不 同，它与 2015 年 4 月 25 日发生在尼泊尔博克拉 $M_{\mathrm{S}} 8.1$ 大地震, 2013 年3月 11 日发生在日本东北部的 $M_{\mathrm{S}} 9.1$ 大 地震均不同; 亦与 2004 年发生在苏门答腊的 $M_{\mathrm{S}} 9.1$ 大 地震不相同. 它们都是发生在两大板块强烈运移与 碰撞作用下的产物, 而2008年5月 12 日发生在汶川-
映秀的 $M_{\mathrm{S}} 8.0$ 大地震，2001年11月 14 日发生在昆仑山 西侧的 $M_{\mathrm{S}} 8.1$ 大地震，2010年4月 14 日发生在玉树的 $M_{\mathrm{S}} 7.1$ 级强烈地震均不同. 因为后者均发生在板

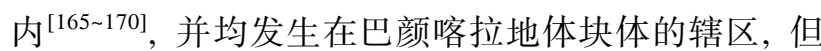
其孕育与发生的物理机理和深部背景及环境不完全 相同，即各自有其本身不同的边界条件和孕育与发 生的特点.

\section{2 汶川-映秀 $M_{\mathrm{S}} 8.0$ 大地震的动力源}

汶川 $M_{\mathrm{S}} 8.0$ 大地震的动力来源应为印度洋板块与 欧亚板块在近南北向的强力碰撞、挤压力系 $\left(F_{\mathrm{c}}\right)$ 和喜 马拉雅弧形山系东部弧顶, 即东构造结向北“挺进” 插人青藏高原东缘力系 $\left(f_{\mathrm{k}}\right)$ 的作用, 即为二者的耦合 力系 $F\left(F=F_{\mathrm{c}}+f_{\mathrm{k}}\right)$ 共同作用下导致了青藏高原东北缘构 造和地震的强烈活动.

第一，青藏高原东北缘壳、幔物质的力系作用. $F_{\mathrm{c}}$ 乃是印度洋板块与欧亚板块强烈碰撞、挤压作用 下，驱动着高原腹地壳、幔物质向东流展形成的作用 
力, $f_{\mathrm{k}}$ 乃是东构造结在两大板块作用下, 它向高原东 北缘“挺进”、插人 ${ }^{[171]}$, 并驱动高原物质向东(SEE)、 转而向东南运移的作用力.

高原腹地的壳、幔物质在 $F_{\mathrm{c}}$ 与 $f_{\mathrm{k}}$ 共同作用下, 沿 海原断裂、东昆仑断裂、鲜水河断裂、嘉黎断裂, 即 沿这4条大的走滑型断裂所辖的 (1) (3)三条通道向东 (SEE)与向南 $(\mathrm{ES})$ 运移(图 10).

第二, 壳、幔物质运移通道与汶川 $M_{\mathrm{S}} 8.0$ 大地震 发生的力系及(2)通道的物质流展. 高原腹地壳、幔物 质向东流展清晰表明(图 10), (1)通道的壳、幔物质在 向东运移进程中, 遇到鄂尔多斯盆地西南角域的阻 隔，迫使部分物质沿西秦岭向东运动; (2)通道的壳、 幔物质在向东运移进程中, 遇到四川盆地坚硬壳、幔 物质的阻隔，迫使这一地域的壳、幔物质重新分异、 调整, 深部物质和能量进行着强烈的交换, 并驱动着 壳、幔盖层以上物质以深度为 $20 \pm 5 \mathrm{~km}$ 处的低速层为 第一滑移面, 以上地幔软流层顶部为第二滑移面沿 龙门山断裂系陡峭主断层面向上逆冲; (3)通道的壳、 幔物质沿鲜水河断裂、安宁河断裂-侧本河-小江断裂 和嘉黎断裂所辖通道向南, 转而向东南运移, 并在南 部与红河断裂汇合后继续向东南(SSE)运动.

显而易见，(1)和(3)通道壳、幔物质向东与向东南 运动造成了其所辖地带构造运动 “活化”或强化, 而 通道内的壳、幔物质则在龙门山地带聚集, 向上运移 (图8), 并在与龙门山断裂系的3条断裂向下收玫过程 中, 即在二者强烈碰撞处发生了这次 $M_{\mathrm{S}} 8.0$ 大地震 (图11).

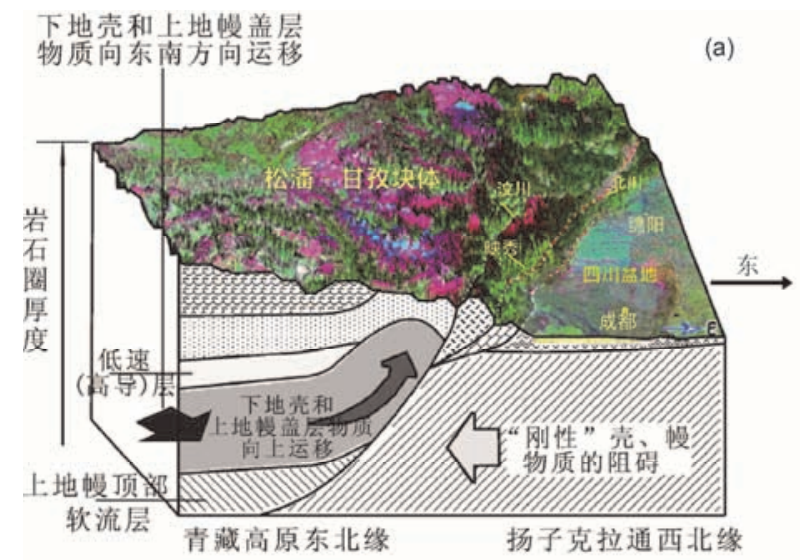

\section{5 结论}

汶川-映秀 $M_{\mathrm{S}} 8.0$ 大地震的孕育、发展和发生是在 两陆-陆板块强烈碰撞、挤压和东构造结向北“挺进”

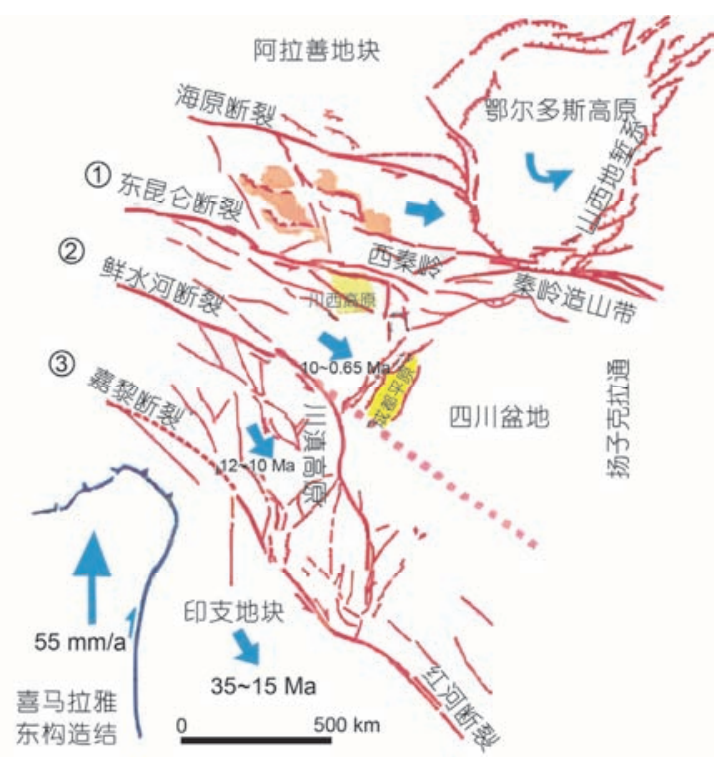

图 10 青藏高原东北地域深部物质流展轨迹分布示意图. (1)通道, 海原断裂与东昆仑断裂所辖物质流动通道; (2)通道, 东昆仑断裂与 鲜水河断裂所辖物质流动通道; (3)通道, 鲜水河断裂与嘉黎断裂所 辖物质流动通道

Figure 10 Sketch map for the three flow locus of deep matter in northeast region. Channel (1) denotes the flowing materials constrained by the Haiyuan fault and the eastern Kunlun fault. Channel (2) denotes the flowing materials constrained by the eastern Kunlun fault and the Xianshuihe fault. Channel (3) denotes the flowing materials constrained by the Xianshuihe fault and the Jiali fault

图 11 汶川-映秀 $M_{\mathrm{S}} 8.0$ 地震形成与深部物质运移模型 ${ }^{[45]}$. (a) 壳、幔物质相向运动轨迹; (b) 强烈碰撞与地震的发生

Figure 11 Model for the Wenchuan-Yingxiu $M_{\mathrm{S}} 8.0$ strong earthquake and deep material motion ${ }^{[45]}$. (a) Locus for opposite motion of crust and upper mantle; (b) $M_{\mathrm{S}} 8.0$ earthquake occurrence by strong collision

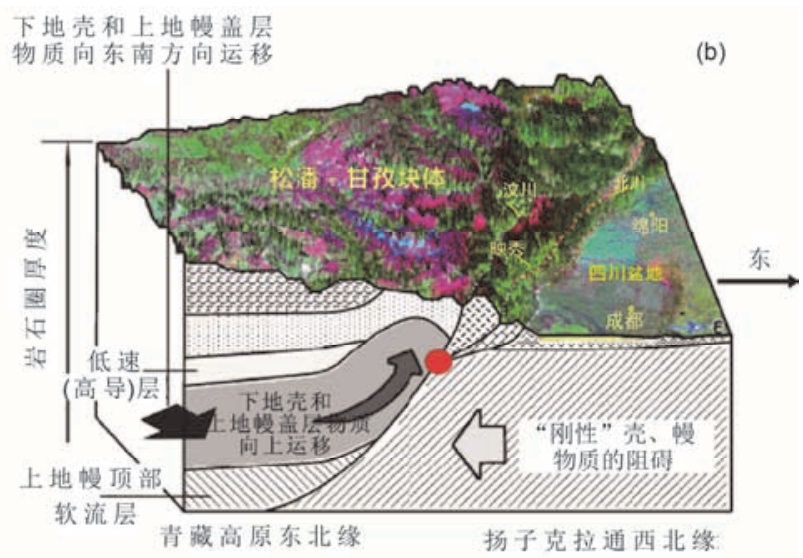


插人青藏高原东缘, 即在其力系共同作用下, 造成青 藏高原东北缘构造和地震强烈活动背景下的产物. 本 文提出了龙门山断裂系及其两侧的壳、幔结构概念模 型和汶川-映秀 $M_{\mathrm{S}} 8.0$ 大地震形成的动力学示意模型, 并取得了以下的新认识: (1) 龙门山断裂系地带是川 西高原与四川盆地壳、幔物质的突变带, 其变化幅度 达15 20 km的特异地域; (2) 龙门山断裂系地带是重 力布格异常差异的界域, 是区别于其两侧重力场不均 衡的特异地带; (3) 龙门山地表3条断裂系不是汶川映秀 $M_{\mathrm{S}} 8.0$ 大地震的发震断层, 而震源深 $15 \pm 5 \mathrm{~km}$ 处的
汇聚断裂才是这次大地震的发震断裂. 该汇聚断裂乃 为一半径为 $5 \mathrm{~km}$, 长达 $300 \mathrm{~km}$ 以上的一个应力集中 的柱状断裂体, 即地震震源是一个体积. (4) 龙门山映秀 $M_{\mathrm{S}} 8.0$ 大地震乃孕育、发展与发生的力源为印度 洋板块与亚欧板块碰撞、挤压力系和东部弧顶, 即东 构造结向北(NNE)“挺进”, 插人效应叠加作用下, 高 原腹地地壳、幔物质向东(NEE)运动受阻, 应力集中, 物质重新分异调整, 并进行着物质与能量的强烈交 换, 故驱使其沿龙门山断裂系的陡峭断层面向上逆冲 与浅部向下收玫的断裂强烈碰撞的结果.

\section{参考文献}

1 Copley A, Dan M K. Models of crustal flow in the India-Asia collision zone. Geophys J Int, 2007, 169: 683-698

2 Yang Z X, Waldhauser F, Chen Y T, et al. Double-difference relocation of earthquakes in central-western China, 1992-1999. J Seismol, 2005, 9: 241-264

3 Wen X Z, Zhang P Z, Du F, et al. The background of historical and modern seismic activities of the occurrence of the $2008 M_{\mathrm{S}} 8.0 \mathrm{Wen}-$ chuan, Sichuan, earthquake (in Chinese). Chin J Geophys, 2009, 52: 444-454 [闻学泽, 张培震, 杜方, 等. 2008 年汶川 8.0 级地震发生 的历史与现今地震活动背景. 地球物理学报, 2009, 52: 444-454]

4 Hubbard J, Shaw J H, Klinger Y. Structural setting of the 2008 Mw 7.9 Wenchuan, China, earthquake. Bull Seismol Soc Am, 2010, 100: 2713-2735

5 Zhang P Z. A review on active tectonics and deep crustal processes of the Western Sichuan region, eastern margin of the Tibetan Plateau. Tectonophysics, 2013, 584: 7-22

6 Beaumont C, Jamieson R A, Mai H N, et al. Crustal channel flows: 1. Numerical models with applications to the tectonics of the Himalayan-Tibetan orogen. J Geophys Res-Solid Earth, 2004, 109: 1-29

7 Burchfiel B C, Royden L H, Hilst R D V D, et al. A geological and geophysical context for the Wenchuan earthquake of 12 May 2008 , Sichuan, People's Republic of China. GSA Today, 2008, 18: 4-11

8 Richardson N J, Densmore A L, Seward D, et al. Extraordinary denudation in the Sichuan Basin: Insights from low-temperature thermochronology adjacent to the eastern margin of the Tibetan Plateau. J Geophys Res-Solid Earth, 2008, 113: 1-23

$9 \mathrm{Xu} \mathrm{X} \mathrm{W,} \mathrm{Wen} \mathrm{X} \mathrm{Z,} \mathrm{Ye} \mathrm{J} \mathrm{Q,} \mathrm{et} \mathrm{al.} \mathrm{The} M_{\mathrm{S}} 8.0$ Wenchuan earthquake surface reptures and its seismogenic structure (in Chinese). Seismol Geol, 2008, 30: 597-629 [徐锡伟, 闻学泽, 叶建青, 等. 汶川 $M_{\mathrm{S}} 8.0$ 地震地表破裂带及其发震构造. 地震地质, 2008, 30: 597-629]

10 Wang E C, Meng Q R. Mesozoic and Cenozoic tectonic evolution of the Longmenshan fault belt. Sci China Ser D-Earth Sci, 2009, 52: 575-592 [王二七, 孟庆任. 对龙门山中生代和新生代构造演化的讨论. 中国科学 D 辑：地球科学, 2008, 38: 1221-1233]

11 Zhang Y Q, Yang N, Shi W, et al. Neotectonics of eastern Tibet and its control on the Wenchuan earthquake (in Chinese). Acta Geol Sin, 2008, 82: 1668-1678 [张岳桥, 杨农, 施炜, 等. 青藏高原东缘新构造及其对汶川地震的控制作用. 地质学报, 2008, 82: 1668-1678]

12 Zhang P Z, Wen X Z, Xu X W, et al. Tectonic model of the great Wenchuan earthquake of May 12, 2008, Sichuan, China (in Chinese). Chin Sci Bull, 2009, 54: 944-953 [张培震, 闻学泽, 徐锡伟, 等. 2008 年汶川 8.0 级特大地震孕育和发生的多单元组合模式. 科学通 报, 2009, 54: 944-953]

13 Zhang P Z, Xu X W, Wen X Z, et al. Slip rates and recurrence intervals of the Longmen Shan active fault zone and tectonic implications for the mechanism of the May 12 Wenchuan earthquake, 2008, Sichuan, China (in Chinese). Chin J Geophys, 2008, 51: 1066-1073 [张培 震, 徐锡伟, 闻学泽, 等. 2008 年汶川 8.0 级地震发震断裂的滑动速率、复发周期和构造成因. 地球物理学报, 2008, 51: 1066-1073]

14 Chen L C, Ran Y K, Chen J, et al. Geological and geomorphic evidence for repeatedly occurring severe earthquakes on fronter-range fault of Longmenshan, China (in Chinese). Quat Sci, 2009, 29: 472-483 [陈立春, 再勇康, 陈杰, 等. 龙门山前山断裂大地震原地重 复发生的地质地貌证据. 第四纪研究, 2009, 29: 472-483]

Hubbard J, Shaw J H. Uplift of the Longmen Shan and Tibetan Plateau, and the 2008 Wenchuan ( $M=7.9)$ earthquake. Nature, 2009, 458: 194-197

16 Li Y, Huang R Q, Zhou R J, et al. Geological background of Longmenshan seismic belt and surface ruptures in Wenchuan earthquake (in Chinese). J Eng Geol, 2009, 17: 3-18 [李勇, 黄润秋, 周荣军, 等. 龙门山地震带的地质背景与汶川地震的地表破裂. 工程地质 学报, 2009, 17: 3-18]

17 Ma Y S, Long C X, Tan C X, et al. Co-seismic faults and geological hazards and incidence of active fault of Wenchuan $M_{\mathrm{S}} 8.0$ earthquake, 
Sichuan, China. Acta Geol Sin, 2009, 83: 713-723

18 Peng H, Ma X M, Jiang J J. Process analysis of in-situ strain during the $M_{\mathrm{S}} 8.0$ Wenchuan earthquake-Data from the stress monitoring station at Shandan. Acta Geol Sin, 2009, 83: 754-766

19 Zhou Y S, He C R. The rheological structures of crust and mechanics of high-angle reverse fault slip for Wenchuan $M_{\mathrm{S}} 8.0$ earthquake (in Chinese). Chin J Geophys, 2009, 52: 474-484 [周永胜, 何昌荣. 汶川地震区的流变结构与发震高角度逆断层滑动的力学条件. 地球 物理学报, 2009, 52: 474-484]

20 Li H B, Si J L, Pei J L, et al. Investigating the surface ruputre process of the Wenchuan earthquake ( $\left.M_{\mathrm{S}} 8.0\right)$ (in Chinese). Quat Sci, 2010, 30: 677-698 [李海兵, 司家亮, 裴军令, 等. 汶川地震 $\left(M_{S} 8.0\right)$ 地表破裂过程探讨. 第四纪研究, 2010, 30: 677-698]

21 Deng Q D, Chen G H, Zhu A L. Discussion of rupture mechanisms on the seismogenic fault of the $2008 M_{\mathrm{S}} 8.0$ Wenchuan earthquake. Sci China Earth Sci, 2011, 54: 1360-1377

22 Yan D P, Li S B, Cao W T, et al. Multi-layer detachment crustal structure in the Longmen Mountains: Evidences from neo-tectonic deformation and geophysical data (in Chinese). Earth Sci Front, 2010, 17: 106-116 [颜丹平，李书兵，曹文涛，等. 龙门山多层分层拆离 地壳结构: 新构造变形与深部构造证据. 地学前缘, 2010, 17: 106-116]

23 Yin A. A special issue on the great 12 May 2008 Wenchuan earthquake ( $M \mathrm{w} 7.9$ ): Observations and unanswered questions preface. Tectonophysics, 2010, 491: 1-9

24 Zhang Z J, Yuan X H, Yun C, et al. Seismic signature of the collision between the east Tibetan escape flow and the Sichuan Basin. Earth Planet Sci Lett, 2010, 292: 254-264

25 Fu B H, Shi P L, Wang P, et al. Geometry and kinematics of the 2008 Wenchuan earthquake surface ruptures around the Qushan Town of Beichuan County, Sichuan: Implications for mitigation of seismic and geologic disasters (in Chinese). Chin J Geophys, 2009, 52: 485-495 [付碧宏, 时丕龙, 王萍, 等. 2008 年汶川地震断层北川段的几何学与运动学特征及地震地质灾害效应. 地球物理学报, 2009, 52: 485-495]

26 Wang Q, Yuan G. Rayleigh wave phase velocity tomography and strong earthquake activity on the southeastern front of the Tibetan Plateau. Sci China Earth Sci, 2014, 57: 2532-2542

27 Teng J W, Bai D H, Yang H, et al. Deep processes and dynamic response associated with the Wenchuan $M_{\mathrm{S}} 8.0$ earthquake of 2008 (in Chinese). Chin J Geophys, 2008, 51: 1385-1402 [滕吉文, 白登海, 杨辉, 等. 2008 汶川 $M_{\mathrm{S}} 8.0$ 地震发生的深层过程和动力学响应. 地球物理学报, 2008, 51: 1385-1402]

28 Wang Z, Wang X B, Huang R X, et al. Deep structure imaging of multi-geophysical parameters and seismogenesis in the Longmenshan fault zone (in Chinese). Chin J Geophys, 2017, 60: 2068-2079 [王志, 王绪本, 黄润秋, 等. 龙门山断裂带多参数深部结构成像与地 震成因研究. 地球物理学报, 2017, 60: 2068-2079]

29 Wei W B, Unsworth M, Jones A, et al. Detection of widespread fluids in the Tibetan crust by magnetotelluric studies. Science, 2001, 292: 716-718

30 Sun J, Jin G W, Bai D H, et al. Sounding of electrical structure of the crust and upper mantle along the eastern border of Qinghai-Tibet Plateau and its tectonic significance. Sci China Ser D-Earth Sci, 2003, 46: 243-253 [孙洁, 晋光文, 白登海, 等. 青藏高原东缘地壳、 上地幔电性结构探测及其构造意义. 中国科学 D 辑：地球科学, 2003, 33: 173-180]

31 Clark M K, Royden L H. Topographic ooze: Building the eastern margin of Tibet by lower crustal flow. Geology, 2000, 28: 703-706

32 Clark M K, Bush J W M, Royden L H. Dynamic topography produced by lower crustal flow against rheological strength heterogeneities bordering the Tibetan Plateau. Geophys J Roy Astron Soc, 2005, 162: 575-590

33 Zhu S B, Shi Y L. Genetic algorithm-finite element inversion of drag forces exerted by the lower crust on the upper crust in the Sichuan-Yunnan area (in Chinese). Chin J Geophys, 2004, 47: 232-239 [朱守彪, 石耀霖. 用遗传有限单元法反演川滇下地壳流动对上 地壳的拖曳作用. 地球物理学报, 2004, 47: 232-239]

34 Klemperer S L. Crustal flow in Tibet: Geophysical evidence for the physical state of Tibetan lithosphere, and inferred patterns of active flow. Geol Soc Lon Spec Publ, 2006, 268: 265-308

35 Schoenbohm L M, Burchfiel B C, Liangzhong C. Propagation of surface uplift, lower crustal flow, and Cenozoic tectonics of the southeast margin of the Tibetan Plateau. Geology, 2006, 34: 813-816

36 Royden L H. Coupling and decoupling of crust and mantle in convergent orogens: Implications for strain partitioning in the crust. J Geophys Res-Solid Earth, 1996, 101: 17679-17705

37 Royden L H, Burchfiel B C, King R W, et al. Surface deformation and lower crustal flow in eastern Tibet. Science, 1997, 276: 788-790

38 Zhao G Z, Chen X B, Wang L F, et al. Evidence of crustal 'channel flow' in the eastern margin of Tibetan Plateau from MT measurements. Chin Sci Bull, 2008, 53: 1887-1893 [赵国泽, 陈小斌, 王立凤, 等. 青藏高原东边缘地壳“管流”层的电磁探测证据. 科学通 报, 2008, 3: 345-350]

39 Wang C Y, Lou H, Lü Z Y, et al. S-wave crustal and upper mantle's velocity structure in the eastern Tibetan Plateau-Deep environment of lower crustal flow. Sci China Ser D-Earth Sci, 2008, 51: 263-274 [王椿镛, 楼海, 吕智勇, 等. 青藏高原东部地壳上地幔 S 波速度 
结构一一地壳流的深部环境. 中国科学 D 辑: 地球科学, 2008, 38: 22-32]

40 Zhu J S. The Wenchuan earthquake occurrence background in deep structure and dynamics of lithosphere (in Chinese). J Chengdu Univ Tech (Sci Tech Ver), 2008, 35: 348-356 [朱介寿. 汶川地震的岩石圈深部结构与动力学背景. 成都理工大学学报(自然科学版), 2008, 35: 348-356]

41 Zhu J S, Wang X B, Yang Y H, et al. The crustal flow beneath the eastern margin of the Tibetan Plateau and its process of dynamics (in Chinese). Chin J Geophys, 2017, 60: 2038-2057 [朱介寿，王绪本，杨宜海，等. 青藏高原东缘的地壳流及动力过程. 地球物理学报, 2017, 60: 2038-2057]

42 Jia S X, Liu B J, Xu Z F, et al. The crustal structures of the central Longmenshan along and its margins as related to the seismotectonics of the 2008 Wenchuan earthquake. Sci China Ser D-Earth Sci, 2014, 57: 777-790 [嘉世旭, 刘保金, 徐朝繁, 等. 龙门山中段及两侧 地壳结构与汶川地震构造. 中国科学: 地球科学, 2014, 44: 497-509]

43 Li J, Wang X B, Li D H, et al. Characteristics of the lithosphere physical structure in eastern margin of the Qinghai-Tibet Plateau and their deep tectonic implications (in Chinese). Chin J Geophys, 2017, 60: 2500-2511 [李军, 王绪本，李大虎，等. 青藏高原东缘岩石 圈物性结构特征及深部构造涵义. 地球物理学报, 2017, 60: 2500-2511]

44 Chen Z, Burchfiel B C, Liu Y, et al. Global positioning system measurements from eastern Tibet and their implications for India/Eurasia intercontinental deformation. J Geophys Res-Solid Earth, 2000, 105: 16215-16227

45 Teng J W, Pi J L, Yang H, et al. Wenchuan-Yingxiu $M_{\mathrm{S}} 8.0$ earthquake seismogenic faults and deep dynamic response (in Chinese). Chin $\mathrm{J}$ Geophys, 2014, 57: 392-403 [滕吉文, 皮娇龙, 杨辉, 等. 汶川-映秀 $M_{\mathrm{S}} 8.0$ 地震的发震断裂带和形成的深层动力学响应. 地球物 理学报, 2014, 57: 392-403]

46 Teng J W, Yang H, Zhang H S, et al. Wenchuan $M_{\mathrm{S}} 8.0$ earthquak, fine velocity structures lithoshpere and dynamical mechanism (in Chinese). Quat Sci, 2010, 30: 637-651 [滕吉文, 杨辉, 张洪双, 等. 汶川-映秀 8.0 级大地震的发生与岩石圈精细速度结构和动力机 制. 第四纪研究, 2010, 30: 637-651]

47 Teng J W, Zhang Y Q, Yan Y F. Deep process of the rupture of strong earthquakes and exploration for the impending earthquake prediction (in Chinese). Chin J Geophys, 2009, 52: 428-443 [滕吉文, 张永谦, 间雅芬. 强烈地震震源破裂和深层过程与地震短临预测探 索. 地球物理学报, 2009, 52: 428-443]

48 Zhang Y. Inversion of source rupture process (in Chinese). Doctor Dissertation. Beijing: Peking University, 2008 [张勇. 震源破裂过程 反演方法研究. 博士学位论文. 北京: 北京大学, 2008

49 Wang W M, Zhao L F, Li J, et al. Rupture process of the $M_{\mathrm{S}} 8.0$ Wenchuan earthquake of Sichuan, China (in Chinese). Chin J Geophys, 2008, 51: 1403-1410 [王卫民, 赵连锋, 李娟, 等. 四川汶川 8.0 级地震震源过程. 地球物理学报, 2008, 51: 1403-1410]

50 He P C, Shen Z K. Rupture triggering process of Wenchuan earthquake seismogenic faults (in Chinese). Chin J Geophys, 2014, 57: 3308-3317 [贺鹏超, 沈正康. 汶川地震发震断层破裂触发过程. 地球物理学报, 2014, 57: 3308-3317]

51 Chen Q F, Hua C, Li L, et al. Viscoelastic simulation of deep tectonic deformation of the Longmenshan fault zone and its implication for strong earthquakes (in Chinese). Chin J Geophys, 2015, 58: 4129-4137 [陈棋福, 华诚, 李乐, 等. 龙门山断裂带深部构造变形的黏弹 性模拟及其与强震活动的关联性探讨. 地球物理学报, 2015, 58: 4129-4137]

52 He F J, Liang C T, Yang Y H, et al. The crust structure of the unruptured segment between Wenchuan and Lushan earthquakes revealed by receiver functions (in Chinese). Chin J Geophys, 2017, 60: 2130-2146 [何富君, 梁春涛, 杨宜海, 等. 用接收函数方法研究汶川和 芦山地震之间未破裂段的地壳结构. 地球物理学报, 2017, 60: 2130-2146]

53 Wang C Y, Li Y H, Lou H. Issues on crustal and upper-mantle structures associated with geodynamics in the northeastern Tibetan Plateau (in Chinese). Chin Sci Bull, 2016, 61: 2239-2263 [王椿镛, 李永华, 楼海. 与青藏高原东北部地球动力学相关的深部构造问题. 科学通报, 2016, 61: 2239-2263]

54 Zhang X Y, Gao R, Bai Z M, et al. Crustal structure beneath the Longmenshan area in eastern Tibet: New constrains from reprocessing wide-angle seismic data of the Aba-Longmenshan-Suining profile (in Chinese). Chin J Geophys, 2017, 60: 2200-2212 [张新彦, 高锐, 白志明, 等. 阿坝-遂宁宽角地震剖面重建藏东缘龙门山地区地壳速度结构. 地球物理学报, 2017, 60: 2200-2212]

55 Chen X B, Wu Y Q, Du P S. The structural features of crustal velocity on both sides of Longmenshan tectonic belt (in Chinese). In: Research and Development of Deep Structure in Mainland China. Beijing: Geology Press, 1988 [陈学波, 吴跃强, 杜平山. 龙门山构造带 两侧地壳速度结构特征. 见: 中国大陆深部构造的研究与进展. 北京: 地质出版社, 1988]

56 Li S L, Zhang X K, Zhang C K, et al. A preliminary study on the crustal velocity structure of Maqin-Lanzhou-Jingbian by means of deep seismic sounding profile (in Chinese). Chin J Geophys, 2002, 45: 210-217 [李松林, 张先康, 张成科, 等. 玛沁-兰州-靖边地震测深剖 面地壳速度结构的初步研究. 地球物理学报, 2002, 45: 210-217]

57 Wang Y X, Mooney W D, Han G H. Crustal P-wave velocity structure from Altyn Tagh to Longmen mountains along the Taiwan-Altay geoscience transect (in Chinese). Chin J Geophys, 2005, 48: 98-106 [王有学, Mooney W D, 韩果花, 等. 台湾-阿尔泰地学断面阿尔 金-龙门山剖面的地壳纵波速度结构. 地球物理学报, 2005, 48: 98-106]

Zhou Y M, Zhang Y S, Shi Y M, et al. Three-dimensional crustal velocity structure in the northeastern margin of the Qinghai-Tibetan 
Plateau (in Chinese). Prog Geophys, 2006, 21: 127-134 [周民都, 张元生, 石雅鏐, 等. 青藏高原东北缘地壳三维速度结构. 地球物 理学进展, 2006, 21: 127-134]

59 Jia S X, Zhang X K. Study on the crust phases of deep seismic sounding experiments and fine crust structures in the northeast margin of Tibetan Plateau (in Chinese). Chin J Geophys, 2008, 51: 1431-1443 [嘉世旭, 张先康. 青藏高原东北缘深地震测深震相研究与地壳 细结构. 地球物理学报, 2008, 51: 1431-1443]

60 Guo W B, Jia S X, Duan Y H, et al. A study on the basement tectonic units in the northeast margin of Tibetan Plateau-The result of Maduo-Gonghe-Yabrai refraction profile (in Chinese). Chin J Geophys, 2016, 59: 3627-3636 [郭文斌，嘉世旭，段永红，等. 青藏高原 东北缘基底结构研究——玛多-共和-雅布赖剖面上地壳地震折射探测. 地球物理学报, 2016, 59: 3627-3636]

61 Lin J Y, Duan Y H. Upper crustal structure of Haiyuan tectonic zone and its surrounding areas (in Chinese). Acta Seismol Sin, 2016, 38: 179-187 [林吉炎, 段永红. 海原构造区及其周缘上部地壳结构研究. 地震学报, 2016, 38: 179-187]

62 Song W J, Zhu J S, Cheng X Q, et al. Deep crustal structure around the source area of the Wenchuan $M_{\mathrm{S}} 8.0$ earthquake (in Chinese). Quat Sci, 2010, 30: 670-676 [宋文杰, 朱介寿, 程先琼, 等. 汶川 $M_{\mathrm{S}} 8.0$ 级地震震源区地壳深部结构研究. 第四纪研究, 2010, 30: 670-676]

63 Wang H Y, Gao R, Li Q S, et al. Deep seismic reflection profiling in the Songpan-west Qinling-Linxia basin of the Qinghai-Tibet Plateau: Data acquisition, data processing and preliminary interpretations (in Chinese). Chin J Geophys, 2014, 57: 1451-1461 [王海燕, 高锐, 李秋 生, 等. 青藏高原松潘-西秦岭-临夏盆地深地震反射剖面——采集、处理与初步解释. 地球物理学报, 2014, 57: 1451-1461]

64 Liu Q Y, Hilst R D V D, Li Y, et al. Eastward expansion of the Tibetan Plateau by crustal flow and strain partitioning across faults. Nat Geosci, 2014, 7: 361-365

65 Wang C Y, Flesch L M, Chang L J, et al. Evidence of active mantle flow beneath South China. Geophys Res Lett, 2013, 40: 5137-5141

66 Chen J H, Liu Q Y, Li S C, et al. Crust and upper mantle S-wave velocity structure across Northeastern Tibetan Plateau and Ordos block (in Chinese). Chin J Geophys, 2005, 48: 333-342 [陈九辉, 刘启元, 李顺成, 等. 青藏高原东北缘-鄂尔多斯地块地壳上地幔 S 波速 度结构. 地球物理学报, 2005, 48: 333-342]

67 Ding Z F, He Z Q, Sun W G, et al. 3-D crust and upper mantle velocity structure in eastern Tibetan Plateau and its surrounding areas (in Chinese). Chin J Geophys, 1999, 42: 197-205 [丁志峰，何正勤，孙为国，等. 青藏高原东部及其边缘地区的地壳上地幔三维速度结 构. 地球物理学报, 1999, 42: 197-205]

$68 \mathrm{Li} \mathrm{Y} \mathrm{H,} \mathrm{Wu} \mathrm{Q} \mathrm{J,} \mathrm{An} \mathrm{Z} \mathrm{H,} \mathrm{et} \mathrm{al.} \mathrm{The} \mathrm{Poisson} \mathrm{ratio} \mathrm{and} \mathrm{crustal} \mathrm{structure} \mathrm{across} \mathrm{the} \mathrm{NE} \mathrm{Tibetan} \mathrm{Plateau} \mathrm{determined} \mathrm{from} \mathrm{receiver} \mathrm{functions}$ (in Chinese). Chin J Geophys, 2006, 49: 1359-1368 [李永华, 吴庆举, 安张辉, 等. 青藏高原东北缘地壳 S 波速度结构与泊松比及其 意义. 地球物理学报, 2006, 49: 1359-1368]

69 Liang C T, Song X D. A low velocity belt beneath northern and eastern Tibetan Plateau from Pn tomography. Geophys Res Lett, 2006, 33: $121-132$

70 Shen W S, Ritzwoller M H, Kang D, et al. A seismic reference model for the crust and uppermost mantle beneath China from surface wave dispersion. Geophys J Int, 2016, 206: ggw175

$71 \mathrm{Xu} \mathrm{Y,} \mathrm{Li} \mathrm{Z,} \mathrm{Huang} \mathrm{R,} \mathrm{et} \mathrm{al.} \mathrm{Seismic} \mathrm{structure} \mathrm{of} \mathrm{the} \mathrm{Longmen} \mathrm{Shan} \mathrm{region} \mathrm{from} \mathrm{S-wave} \mathrm{tomography} \mathrm{and} \mathrm{its} \mathrm{relationship} \mathrm{with} \mathrm{the} \mathrm{Wen-}$ chuan $M_{\mathrm{S}} 8.0$ earthquake on 12 May 2008, southwestern China. Geophys Res Lett, 2010, 37: 211-228

72 Li S H, Wang Y B, Liang Z B, et al. Crustal structure in southeastern Gansu from regional seismic waveform inversion (in Chinese). Chin J Geophys, 2012, 55: 1186-1197 [李少华，王彦宾，梁子斌，等. 甘肃东南部地壳速度结构的区域地震波形反演. 地球物理学 报, 2012, 55: 1186-1197]

73 Wang C Y, Sandvol E, Zhu L, et al. Lateral variation of crustal structure in the Ordos block and surrounding regions, North China, and its tectonic implications. Earth Planet Sci Lett, 2014, 387: 198-211

74 Yang Y J, Ritzwoller M H, Zheng Y, et al. A synoptic view of the distribution and connectivity of the mid-crustal low velocity zone beneath Tibet. J Geophys Res-Solid Earth, 2012, 117: B04303

75 Deng W Z, Chen J H, Guo B, et al. Fine velocity structure of the Longmenshan fault zone by double-difference tomography (in Chinese). Chin J Geophys, 2014, 57: 1101-1110 [邓文泽, 陈九辉, 郭造, 等. 龙门山断裂带精细速度结构的双差层析成像研究. 地球物理学 报, 2014, 57: 1101-1110]

76 Liu Q M, Zhao J M, Lu F, et al. Crustal structure of northeastern margin of the Tibetan Plateau by receiver function inversion. Sci China Earth Sci, 2014, 57: 741-750 [刘启民, 赵俊猛, 卢芳, 等. 用接收函数方法反演青藏高原东北缘地壳结构. 中国科学: 地球科学, 2014, 44: 668-679]

77 Zhang Y, Cheng S Y, Zhao B K, et al. The feature of tectonics in the Tibet Plateau from new regional gravity signals (in Chinese). Chin J Geophys, 2013, 56: 1369-1380 [张燕, 程顺有, 赵炳坤, 等. 青藏高原构造结构特点:新重力异常成果的启示. 地球物理学报, 2013, 56: 1369-1380]

78 Li Y H, Pan J T, Wu Q J, et al. Crustal and uppermost mantle structure of SE Tibetan Plateau from Rayleigh-wave group-velocity measurements. Earthq Sci, 2014, 27: 411-419

79 Yu D X, Li Y H, Wu Q J, et al. S-wave velocity structure of the northeastern Tibetan Plateau from joint inversion of Rayleigh wave 
phase and group velocities (in Chinese). Chin J Geophys, 2014, 57: 800-811 [余大新, 李永华, 吴庆举, 等. 利用 Rayleigh 波相速度和 群速度联合反演青藏高原东北缘 S 波速度结构. 地球物理学报, 2014, 57: 800-811]

80 Deng Y F, Shen W S, Xu T, et al. Crustal layering in northeastern Tibet: A case study based on joint inversion of receiver functions and surface wave dispersion. Geophys J Int, 2015, 203: 692-706

81 Pan J T, Li Y H, Wu Q J, et al. Phase velocity maps of Rayleigh waves in the southeast Tibetan Plateau (in Chinese). Chin J Geophys, 2015，58：3993-4006 [潘佳铁，李永华，吴庆举，等. 青藏高原东南部地区瑞利波相速度层析成像. 地球物理学报，2015，58: 3993-4006]

82 Zhang H S, Gao R, Tian X B, et al. Crustal S-wave velocity beneath the northeastern Tibetan Plateau inferred from teleseismic P-wave receiver functions (in Chinese). Chin J Geophys, 2015, 58: 3982-3992 [张洪双，高锐，田小波，等. 青藏高原东北缘地壳 S 波速度结 构及其动力学含义一一远震接收函数提供的证据. 地球物理学报, 2015, 58: 3982-3992]

83 Wang X B, Gao Y, Wang Z, et al. Research progress on deep geophysics and continental dynamics in Eastern Tibetan Plateau (in Chinese). Chin J Geophys, 2017, 60: 2030-2037 [王绪本, 高原, 王志, 等. 青藏高原东缘深部地球物理与大陆动力学研究进展. 地球 物理学报, 2017, 60: 2030-2037]

84 Allam A A, Ben-Zion Y. Seismic velocity structures in the southern California plate-boundary environment from double-difference tomography. Geophys J Int, 2012, 190: 1181-1196

85 Allen C R, Gillespie A R, Han Y, et al. Red River and associated faults, Yunnan Province, China: Quaternary geology, slip rates, and seismic hazard. Geol Soc Am Bull, 1984, 95: 686-700

86 Pesicek J D, Thurber C H, Zhang H, et al. Teleseismic double-difference relocation of earthquakes along the Sumatra-Andaman subduction zone using a 3-D model. J Geophys Res-Solid Earth, 2010, 115: B10303

87 Waldhauser F, Ellsworth W L. A double-difference earthquake location algorithm: Method and application to the northern Hayward fault, California. Bull Seismol Soc Am, 2000, 90: 1353-1368

88 Teng J W, Si X, Wang Q S, et al. Collation and stipulation of the core science problems and theoretical concept in the geoscience study on the Tibetan Plateau (in Chinese). Chin J Geophys, 2015, 58: 103-124 [滕吉文, 司芗, 王谦身, 等. 青藏高原地球科学研究中的核 心问题与理念的厘定. 地球物理学报, 2015, 58: 103-124]

89 Hai L, Wang C Y, Lü Z Y, et al. Deep tectonic setting of the 2008 Wenchuan $M_{\mathrm{S}} 8.0$ earthquake in southwestern China-Joint analysis of teleseismic P-wave receiver functions and Bouguer gravity anomalies. Sci China Ser D-Earth Sci, 2009, 52: 166-179 [楼海, 王椿镛，吕 智勇, 等. 2008 年汶川 $M_{\mathrm{S}} 8.0$ 级地震的深部构造环境——远震 $\mathrm{P}$ 波接收函数和布格重力异常的联合解释. 中国科学 $\mathrm{D}$ 辑: 地球科 学, 2008, 38: 1207-1220]

90 She Y W, Fu G Y, Wang Z H, et al. Vertical tectonic stress in eastern margin of Bayan Har block revealed by gravity and terrain data (in Chinese). Chin J Geophys, 2017, 60: 2480-2492 [余雅文, 付广裕, 王灼华, 等. 重力与地形数据揭示的巴颜喀拉块体东缘垂向构造 应力场. 地球物理学报, 2017, 60: 2480-2492]

91 Shen C Y, Li H, Sun S A, et al. Dynamic variations of gravity and the preparation process of the Wenchuan $M_{\mathrm{S}} 8.0$ earthquake (in Chinese). Chin J Geophys, 2009, 52: 2547-2557 [申重阳, 李辉, 孙少安, 等. 重力场动态变化与汶川 $M_{\mathrm{S}} 8.0$ 地震孕育过程. 地球物理学 报, 2009, 52: 2547-2557]

92 Wang Q S, Teng J W, Zhang Y Q, et al. The effect of crustal gravity isostasy and Wenchuan earthquake in Longmenshan faults and adjacent area (in Chinese). Chin J Geophys, 2008, 23: 1664-1670 [王谦身, 滕吉文, 张永谦, 等. 龙门山断裂系及邻区地壳重力均衡效 应与汶川地震. 地球物理学进展, 2008, 23: 1664-1670]

93 Wang Q S, Teng J W, Zhang Y Q, et al. The crustal structure and gravity isostasy in the middle western Sichuan area (in Chinese). Chin J Geophys, 2009, 52: 579-583 [王谦身, 滕吉文, 张永谦, 等. 四川中西部地区地壳结构与重力均衡. 地球物理学报, 2009, 52: 579-583]

94 Zhang J S, Gao R, Zeng L S, et al. Relationship between characteristics of gravity and magnetic anomalies and the earthquakes in Longmenshan range and adjacent areas (in Chinese). Chin J Geophys, 2009, 52: 572-578 [张季生, 高锐, 曾令森, 等. 龙门山及邻区 重、磁异常特征及与地震关系的研究. 地球物理学报, 2009, 52: 572-578]

95 Zhang J S, Gao R, Li Q S, et al. A study on geophysical characteristic and basement in the Songpan-Garze and Western Qinling Orogenic Belt (in Chinese). Geol Rev, 2007, 53: 261-266 [张季生, 高锐, 李秋生, 等. 松潘-甘孜和西秦岭造山带地球物理特征及基底构造研 究. 地质论评, 2007, 53: 261-266]

96 Zhang Y Q, Wang Q S, Teng J W. The crustal isostatic anomaly beneath eastern Tibet and western Sichuan and its relationship with the distribution of earthquakes (in Chinese). Chin J Geophys, 2010, 53: 2631-2638 [张永谦, 王谦身, 滕吉文. 川西藏东地区的地壳均衡 异常及其与地震分布的关系. 地球物理学报, 2010, 53: 2631-2638]

97 Zhu Y Q, Liu F, Li T M, et al. Dynamic variation of the gravity field in the Sichuan-Yunnan region and its implication for seismic risk (in Chinese). Chin J Geophys, 2015, 58: 4187-4196 [祝意青, 刘芳, 李铁明, 等. 川滇地区重力场动态变化及其强震危险含义. 地球 物理学报, 2015, 58: 4187-4196]

98 Bi B T, Hu X Y, Li L Q, et al. Multi-scale analysis to the gravity field of the northeastern Tibetan Plateau and its geodynamic implications (in Chinese). Chin J Geophys, 2016, 59: 543-555 [毕奔腾, 胡祥云, 李丽清, 等. 青藏高原东北部多尺度重力场及其地球动力 
学意义. 地球物理学报, 2016, 59: 543-555]

99 Meng X H, Shi L, Guo L H, et al. Multi-scale analyses of transverse structures based on gravity anomalies in the northeastern margin of the Tibetan Plateau (in Chinese). Chin J Geophys, 2012, 55: 3933-3941 [孟小红, 石磊, 郭良辉, 等. 青藏高原东北缘重力异常多尺 度横向构造分析. 地球物理学报, 2012, 55: 3933-3941]

100 Zhang S M, Xie F R, Huang Z X, et al. Bending and thrusting of the upper crust in Longmenshan area and its deep dynamics (in Chinese). Quat Sci, 2009，29: 449-463 [张世民, 谢富仁, 黄忠贤, 等. 龙门山地区上地壳的拱曲冲断作用及其深部动力学机制探讨. 第四纪研究, 2009, 29: 449-463]

101 Zhang Y Q, Wang Q S, Teng J W. Crustal isotatic state in western Sichuan and its dynamical mechanism (in Chinese). Quat Sci, 2010, 30: 662-669 [张永谦，王谦身，滕吉文. 川西地区的地壳均衡状态及其动力学机制. 第四纪研究, 2010, 30: 662-669]

102 Li Y. Contiental Dynamic Process and Gelogical Response of the Eastern Margin of Tibetan Plateau (in Chinese). Beijing: Geological Press, 2006 [李勇. 青藏高原东缘大陆动力学过程与地质响应. 北京: 地质出版社, 2006]

103 Bai D H, Unsworth M J, Meju M A, et al. Crustal deformation of the eastern Tibetan Plateau revealed by magnetotelluric imaging. Nat Geosci, 2010, 3: 358-362

104 Unsworth M J, Meju M A. Crustal deformation of the eastern Tibetan Plateau revealed by magnetotelluric imaging. Nat Geosci, 2011, 3: 358-362

105 Zhao B, Shi Y, Gao Y. Seismic relocation, focal mechanism and crustal seismic anisotropy associated with the 2010 Yushu $M_{\mathrm{S}} 7.1$ earthquake and its aftershocks. Acta Seismol Sin, 2012, 25: 111-119

106 Chen Y Z, Tang J, Cai J T, et al. Deep electrical structure beneath the Sichuan-Yunnan area in the eastern margin of the Tibetan Plateau (in Chinese). Chin J Geophys, 2017, 60: 2425-2441 [程远志，汤吉，蔡军涛，等. 青藏高原东缘川滇构造区深部电性结构特征. 地球 物理学报, 2017, 60: 2425-2441]

107 Chen Y Z, Tang J, Chen X B, et al. Electrical structure and seismogenic environment along the border region of Yunnan, Sichuan and Guizhou in the south of the North-South seismic belt (in Chinese). Chin J Geophys, 2015, 58: 3965-3981 [程远志, 汤吉, 陈小斌, 等. 南北地震带南段川滇黔接壤区电性结构特征和孕震环境. 地球物理学报, 2015, 58: 3965-3981]

108 Wang L F, Zhao G Z, Zhan Y, et al. Electric structure of crust beneath the southwestern segment of the Longmenshan fault zone (in Chinese). Seismol Geol, 2014, 36: 302-311 [王立凤, 赵国泽, 詹艳, 等. 龙门山断裂带西南端地壳电性结构. 地震地质, 2014, 36: 302-311]

109 Wang X B, Luo W, Zhang G, et al. Electrical resistivity structure of Longmenshan crust-mantle under sector boundary (in Chinese). Chin J Geophys, 2013, 56: 2718-2727 [王绪本, 罗威, 张刚, 等. 扇形边界条件下的龙门山壳、幔电性结构特征. 地球物理学报, 2013, 56: 2718-2727]

110 Wang X B, Yu N, Gao S, et al. Research progress in research on electrical structure of crust and upper mantle beneath the eastern margin of the Tibetan Plateau (in Chinese). Chin J Geophys, 2017, 60: 2350-2370 [王绪本, 余年, 高嵩, 等. 青藏高原东缘地壳上地幔电性 结构研究进展. 地球物理学报, 2017, 60: 2350-2370]

111 Zhang L T, Jin S, Wei W B, et al. Electrical structure of crust and upper mantle beneath the eastern margin of the Tibetan Plateau and the Sichuan basin (in Chinese). Chin J Geophys, 2012, 55: 4126-4137 [张乐天, 金胜, 魏文博, 等. 青藏高原东缘及四川盆地的壳、幔导 电性结构研究. 地球物理学报, 2012, 55: 4126-4137]

112 Bai D H, Teng J W, Ma X B, et al. Crustal flow beneath eastern Tibetan Plateau revealed by magnetotelluric measurements (in Chinese). Chin Basic Sci, 2011, 13: 7-10 [白登海, 滕吉文, 马晓冰, 等. 大地电磁观测揭示青藏高原东部存在两条地壳物质流. 中国基础科 学, 2011, 13: 7-10]

113 Min G, Wang X B, Xia S B, et al. Electrical structure of middle and upper crust beneath the Minshan uplift zone and central section of the West Qinling orogenic zone (in Chinese). Chin J Geophys, 2017, 60: 2397-2413 [闵刚, 王绪本, 夏时斌, 等. 岷山隆起带与西秦 岭构造带中段中上地壳电性结构特征. 地球物理学报, 2017, 60: 2397-2413]

114 Zhan Y, Yang H, Zhao G Z, et al. Deep electrical structure of crust beneath the Madongshan step area at the Haiyuan fault in the northeastern margin of the Tibetan Plateau and tectonic implications (in Chinese). Chin J Geophys, 2017, 60: 2371-2384 [詹艳, 杨皓, 赵国 泽，等. 青藏高原东北缘海原构造带马东山阶区深部电性结构特征及其构造意义. 地球物理学报, 2017, 60: 2371-2384]

115 Yan Y F, Teng J W, Ruan X M, et al. Aeromagnetic field characteristics and the Wenchuan earthquakes in the Longmenshan mountains and adjacent areas (in Chinese). Chin J Geophys, 2016, 59: 197-214 [间亚芬, 滕吉文, 阮小敏, 等. 龙门山和相邻地域航磁场特征与 汶川大地震. 地球物理学报, 2016, 59: 197-214]

$116 \mathrm{Hu}$ Y P, Wang Z, Liu G N, et al. Crustal structure imaging of multi-geophysical parameters and generating mechanisms of large earthquakes in North-South Seismic Zone (in Chinese). Chin J Geophys, 2017, 60: 2113-2129 [胡亚平, 王志, 刘冠男, 等. 南北地震带地 壳结构多参数成像及强震触发机制研究. 地球物理学报, 2017, 60: 2113-2129]

117 Wang C Y, Chang L J, Lü Z Y, et al. Seismic anisotropy of upper mantle in eastern Tibetan Plateau and related crust-mantle coupling pattern. Sci China Ser D-Earth Sci, 2007, 50: 1150-1160 [王椿镛, 常利军, 吕智勇, 等. 青藏高原东部上地幔各向异性及相关的壳、 幔耦合型式. 中国科学 D 辑: 地球科学, 2007, 37: 495-503] 
118 Zhao P P, Chen J H, Campillo M, et al. Crustal velocity changes associated with the Wenchuan M8.0 earthquake by auto-correlation function analysis of seismic ambient noise (in Chinese). Chin J Geophys, 2012, 55: 137-145 [赵盼盼, 陈九辉, Campillo M, 等. 汶川 地震区地壳速度相对变化的环境噪声自相关研究. 地球物理学报, 2012, 55: 137-145]

11 Zhao P P, Chen J H, Liu Q Y, et al. Fine structure of middle and upper crust of the Longmenshan Fault zone from short period seismic ambient noise (in Chinese). Chin J Geophys, 2015, 58: 4018-4030 [赵盼盼，陈九辉，刘启元，等. 龙门山断裂带中上地壳速度结构的 短周期环境噪声成像. 地球物理学报, 2015, 58: 4018-4030]

120 Gouédard P, Yao H, Ernst F, et al. Surface wave eikonal tomography in heterogeneous media using exploration data. Geophys J Int, 2012, 191: 781-788

121 Lin F C, Ritzwoller M H. Helmholtz surface wave tomography for isotropic and azimuthally anisotropic structure. Geophys J Int, 2011, 186: $1104-1120$

122 Lin F C, Ritzwoller M H, Snieder R. Eikonal tomography: Surface wave tomography by phase front tracking across a regional broad-band seismic array. Geophys J Roy Astron Soc, 2010, 177: 1091-1110

123 Zhu J S, Zhao J M, Jiang X T, et al. Crustal flow beneath the eastern margin of the Tibetan Plateau. Earthq Sci, 2012, 25: 469-483

124 Jin G, Gaherty J B. Surface wave phase-velocity tomography based on multichannel cross-correlation. Geophys J Int, 2015, 201: 1383-1398

125 Zhong S J, Wu J P, Fang L H, et al. Surface wave eikonal tomography in and around the northeastern margin of the Tibetan Plateau (in Chinese). Chin J Geophys, 2017, 60: 2304-2314 [钟世军，吴建平，房立华，等. 青藏高原东北缘及周边地区基于程函方程的面波层 析成像. 地球物理学报, 2017, 60: 2304-2314]

126 Lei J S, Zhao D P. Structural heterogeneity of the Longmenshan fault zone and the mechanism of the 2008 Wenchuan earthquake $\left(M_{\mathrm{S}} 8.0\right)$. Geochem Geophys Geosyst, 2009, 10: 1-17

127 Zheng T Y, Zhao L, Zhu R X. New evidence from seismic imaging for subduction during assembly of the North China Craton: REPLY. Geology, 2010, 38: 395-398

128 Huang Z X, Li H Y, Xu Y. Lithospheric S-wave velocity structure of the North-South Seismic Belt of China from surface wave tomography (in Chinese). Chin J Geophys, 2013, 56: 1121-1131 [黄忠贤, 李红谊, 胥䝠. 南北地震带岩石圈 S 波速度结构面波层析成像. 地球物理学报, 2013, 56: 1121-1131]

129 Lei J S, Zhao D P, Su J R, et al. Fine seismic structure under the Longmenshan fault zone and the mechanism of the large Wenchuan earthquake (in Chinese). Chin J Geophys, 2009, 52: 339-345 [雷建设, 赵大鹏, 苏金蓉, 等. 龙门山断裂带地壳精细结构与汶川地震 发震机理. 地球物理学报, 2009, 52: 339-345]

130 Liu Q Y, Li Y, Chen J H, et al. Wenchuan $M_{\mathrm{S}} 8.0$ earthquake: Preliminary study of the S-wave velocity structure of the crust and upper mantle (in Chinese). Chin J Geophys, 2009, 52: 309-319 [刘启元, 李昱, 陈九辉, 等. 汶川 $M_{\mathrm{S}} 8.0$ 地震: 地壳上地幔 S 波速度结构的 初步研究. 地球物理学报, 2009, 52: 309-319]

131 Wang C Y, Yang W C, Wu J P, et al. Study on the lithospheric structure and earthquakes in North-South Tectonic Belt (in Chinese). Chin J Geophys, 2015, 58: 3867-3901 [王椿镛, 杨文采, 吴建平, 等. 南北构造带岩石圈结构与地震的研究. 地球物理学报, 2015, 58: 3867-3901]

132 Xu X M, Ding Z F, Zhang F X. The teleseismic tomography study by P-wave traveltime data beneath the southern South-north Seismic Zone (in Chinese). Chin J Geophys, 2015, 58: 4041-4051 [徐小明, 丁志峰, 张风雪. 南北地震带南段远震 P 波走时层析成像研究. 地球物理学报, 2015, 58: 4041-4051]

133 He M X, Fang H, Wang X B, et al. Deep conductivity characteristics of the southern Xianshuihe fault zone (in Chinese). Chin J Geophys, 2017, 60: 2414-2424 [何梅兴, 方慧, 王绪本, 等. 鲜水河断裂带南段深部电性结构特征研究. 地球物理学报, 2017, 60: 2414-2424]

134 Wang C Y, Han W B, Wu J P, et al. Crustal structure beneath the eastern margin of the Tibetan Plateau and its tectonic implications. J Geophys Res-Solid Earth, 2007, 112: 1-21

135 Yang H, Teng J W, Pi J L. Numerical simulation of the geodynamical condition about the channel flow model in Tibetan Plateau (in Chinese). Chin J Geophys, 2013, 56: 2625-2635 [杨辉, 滕吉文, 皮娇龙. 青藏高原通道流模型动力环境的数值模拟. 地球物理学报, 2013, 56: 2625-2635]

136 Pi J L, Teng J W, Yang H. Geodynamic response of Moho relief modes to the channel flow below the Tibetan Plateau: Numerical simulation (in Chinese). Chin J Geophys, 2014, 57: 2766-2776 [皮娇龙, 滕吉文, 杨辉. 青藏高原 Moho 界面起伏样式对通道流模型的动 力学响应一一基于数值模拟. 地球物理学报, 2014, 57: 2766-2776]

137 Jia S X, Lin J Y, Guo W B, et al. Investigation on diversity of crustal structures beneath the Bayan Har block (in Chinese). Chin J Geophys, 2017, 60: 2226-2238 [嘉世旭, 林吉炎, 郭文斌, 等. 巴颜喀拉块体地壳结构多样性探测. 地球物理学报, 2017, 60: 2226-2238]

138 Chen Y T. On the magnitude and the fault length of the great Wenchuan earthquake (in Chinese). Sci Tech Rev, 2008, 26: 26-27 [陈运 泰. 汶川特大地震的震级和断层长度. 科技导报, 2008, 26: 26-27]

139 Wu J P, Huang Y, Zhang T Z, et al. Aftershock distribution of the $M_{\mathrm{S}} 8.0$ Wenchuan earthquake and three dimensional P-wave velocity structure in and around source region (in Chinese). Chin J Geophys, 2009, 52: 320-328 [吴建平, 黄媛, 张天中, 等. 汶川 $M_{\mathrm{S}} 8.0$ 级地 震余震分布及周边区域 P 波三维速度结构研究. 地球物理学报, 2009, 52: 320-328] 
140 Zhu A L, Xu X W, Diao G L, et al. Relocation of the $M_{\mathrm{S}} 8.0$ Wenchuan earthquake sequence in part: Preliminary seismotectonic analysis (in Chinese). Seismol Geol, 2008, 30: 759-767 [朱艾斓, 徐锡伟， 刀桂苓，等. 汶川 $M_{\mathrm{S}} 8.0$ 地震部分余震重新定位及地震构造初步分 析. 地震地质, 2008, 30: 759-767]

141 Bai Y Z, Xu X W, Xu J, et al. A research on the distribution of deformation fields near the fault of 2008 Wenchuan earthquake (in Chinese). Chin J Geophys, 2011, 54: 1798-1804 [白玉柱，徐锡伟，徐杰，等. 2008 年汶川地震近断裂区域变形场的空间分布. 地球物理 学报, 2011, 54: 1798-1804]

142 Guo X Y, Gao R, Keller G R, et al. Discussion on the mountain building process of the Longmenshan range (in Chinese). Chin J Geol, 2014, 49: 1337-1345 [郭晓玉, 高锐, Keller G R, 等. 龙门山断裂带隆起造山独特性探讨. 地质科学, 2014, 49: 1337-1345]

143 Yang H, Teng J W, Wang Q S, et al. Numerical simulation on the special gravity fields and dynamic response in Longmenshan orogenic belt and adjacent area (in Chinese). Chin J Geophys, 2013, 56: 106-116 [杨辉, 滕吉文, 王谦身, 等. 龙门山造山带及邻区重力场特 征与动力学响应数值模拟. 地球物理学报, 2013, 56: 106-116]

144 Royden L H, Burchfiel B C, Rd V D H. The geological evolution of the Tibetan Plateau. Science, 2008, 321: 1054-1058

145 Chen G G, Ji F J, Zhou R J, et al. Primary research of activity segmentation of Longmenshan Fault zone since late-Quaternary (in Chinese). Seimol Geol, 2007, 29: 657-673 [陈国光, 计风桔, 周荣军, 等. 龙门山断裂带晚第四纪活动性分段的初步研究. 地震地质, 2007, 29: 657-673]

146 Li H B, Si J L, Fu X F, et al. Co-seismic rupture and maximum displacement of the 2008 Wenchuan earthquake and its tectonic implications (in Chinese). Quat Sci, 2009, 29: 387-402 [李海兵，司家亮，付小方，等. 2008 年汶川地震同震滑移特征、最大滑移量及构造意 义. 第四纪研究, 2009, 29: 387-402]

147 Wang H, Li H B, Pei J L, et al. Structural and lithologic characteristics of the Wenchuan earthquake fault zone and its relationship with the sesimic activities (in Chinese). Quat Sci, 2010, 30: 768-778 [王焕, 李海兵, 裴军令, 等. 汶川地震断裂带结构、岩性特征及其与 地震活动的关系. 第四纪研究, 2010, 30: 768-778]

$148 \mathrm{Xu} \mathrm{J}$, Gao X L, Zhou B G, et al. The seismogenic structure of the 2008 Wenchuan $M_{\mathrm{S}} 8.0$ earthquake: A newly generated deep fault in crust along the Longmen Mountains fault zone in the shallow subsurface (in Chinese). Earth Sci Front, 2010, 17: 117-127 [徐杰, 高祥 林, 周本刚, 等. 2008 年汶川 8.0 级地震的发震构造: 沿龙门山断裂带新生的地壳深部断裂. 地学前缘, 2010, 17: 117-127]

149 Wang C Y, Flesch L M, Silver P G, et al. Evidence for mechanically coupled lithosphere in central Asia and resulting implications. Geology, 2008, 36: 363-366

150 Shan J X, Song X G, Han Y F, et al. The characteristics of surface vertical deformation before the Wenchuan $M_{\mathrm{S}} 8.0$ earthquake from InSAR (in Chinese). Chin J Geophys, 2009, 52: 2739-2745 [单新建, 宋小刚, 韩宇飞, 等. 汶川 $M_{\mathrm{S}} 8.0$ 地震前 InSAR 垂直形变场变化 特征研究. 地球物理学报, 2009, 52: 2739-2745]

151 Shan J X, Zhang G H, Wang C S, et al. Joint inversion for the spatial fault slip distribution of the 2015 Nepal $M$ w 7.9 earthquake based on InSAR and GPS observations (in Chinese). Chin J Geophys, 2015, 58: 4266-4276 [单新建, 张国宏, 汪驰升, 等. 基于 InSAR 和 GPS 观测数据的尼泊尔地震发震断层特征参数联合反演研究. 地球物理学报, 2015, 58: 4266-4276]

152 Li Y H, Wang Q L, Cui D X, et al. Inversion of present-day fault slip, rate along Altyn Tagh Fault constrained by GPS data (in Chinese). Seismol Geol, 2015, 37: 869-879 [李煜航, 王庆良, 崔笃信, 等. 利用 GPS 数据反演阿尔金断裂现今滑动速率. 地震地质, 2015, 37: 869-879]

153 Liu X, Sun D Y, Ma J, et al. Present-day deformation and stress state of Longmenshan fault from GPS results—Comparative research on active faults in Sichuan-Yunnan region (in Chinese). Chin J Geophys, 2014, 57: 1091-1100 [刘峡, 孙东颖, 马瑾, 等. GPS 结果揭示的 龙门山断裂带现今形变与受力——与川滇地区其他断裂带的对比研究. 地球物理学报, 2014, 57: 1091-1100]

154 Xu Z Q, Li H B, Wu Z L. Wenchuan earthquake and scientific drilling (in Chinese). Acta Geol Sin, 2008, 82: 1613-1622 [许志琴, 李海 兵, 吴忠良. 汶川地震和科学钻探. 地质学报, 2008, 82: 1613-1622]

155 Zhang P Z, Wang Q, Ma Z J. GPS velocity field and active crustal blocks of contemporary tectonic deformation in continental China (in Chinese). Earth Sci Front, 2002, 9: 430-441 [张培震, 王琪, 马宗晋. 中国大陆现今构造运动的 GPS 速度场与活动地块. 地学前缘, 2002, 9: 430-441]

156 Xiao Z H, Xu C J, Jiang G Y, et al. Crustal strain in the Longmenshan region considering fault locking during ten years before the 2008 Wenchuan earthquake (in Chinese). Chin J Geophys, 2017, 60: 953-961 [肖卓辉, 许才军, 江国焰, 等. 汶川地震前十年间龙门山区 域顾及断层闭锁的地壳应变场. 地球物理学报, 2017, 60: 953-961]

157 Zhang Z J, Wang Y H, Chen Y, et al. Crustal structure across Longmenshan fault belt from passive source seismic profiling. Geophys Res Lett, 2009, 36: 1397-1413

158 Zhang Y Q, Li H L. Late Quaternary active faulting along the SW segment of the Longmenshan Fault (in Chinese). Quat Sci, 2010, 30: 699-710 [张岳桥, 李海龙. 龙门山断裂带西南段晚第四纪活动性调查与分析. 第四纪研究, 2010, 30: 699-710]

159 Zhang Z Q, Zhang P Z, Wang Q L. The structure and seismogenic mechanism of Longmenshan high dip-angle reverse fault (in Chinese). Chin J Geophys, 2010, 53: 2068-2082 [张竹琪, 张培震, 王庆良. 龙门山高倾角逆断层结构与孕震机制. 地球物理学报, 2010, 53: 2068-2082]

160 Tan K, Yang S M, Qiao X J, et al. Rupture of ramp-décollement faults in the 2008 Wenchuan earthquake-Geodetic evidence for the uplift 
of the Longmenshan driven by convergent deformation (in Chinese). Chin J Geophys, 2013, 56: 1506-1516 [谭凯, 杨少敏, 乔学军, 等. 2008 年汶川地震中断坡-滑脱断层破裂: 龙门山挤压隆升的大地测量证据. 地球物理学报, 2013, 56: 1506-1516]

161 Yang Y H, Chen Q, Liu G X, et al. Correction of coseismic deformation field associated with Wenchuan earthquake with GPS observables and InSAR adjacent track smoothing and fault slip inversion (in Chinese). Chin J Geophys, 2014, 57: 1462-1476 [杨芗辉, 陈强, 刘国祥, 等. 汶川地震同震形变场的 GPS 和 InSAR 邻轨平滑校正与断层滑移精化反演. 地球物理学报, 2014, 57: 1462-1476]

162 Liu Q X, Zhu J S, Cao J X, et al. Relocation of the Wenchuan $M_{\mathrm{S}} 8.0$ earthquake sequence and its aftershocks and their spatial distribution characteristics (in Chinese). Quat Sci, 2010, 30: 736-744 [刘巧霞, 朱介寿, 曹俊兴, 等. 汶川 $M_{\mathrm{S}} 8.0$ 级地震余震重新定位及其空间分 布特征研究. 第四纪研究, 2010, 30: 736-744]

163 Teng J W, Song P H, Zhang X M, et al. The driving force and movement of materials in the Earth's interior (in Chinese). Chin Sci Bull, 2016, 61: 1995-2019 [滕吉文, 宋鹏汉, 张雪梅, 等. 地球内部物质的运动与动力. 科学通报, 2016, 61: 1995-2019]

164 Wang X C, Ding Z F, Wu Y, et al. Crustal thicknesses and Poisson's ratios beneath the northern section of the North-South Seismic belt and surrounding areas in China (in Chinese). Chin J Geophys, 2017, 60: 2080-2090 [王兴臣, 丁志峰，武岩，等. 中国南北地震带北段 及其周缘地壳厚度与泊松比研究. 地球物理学报, 2017, 60: 2080-2090]

165 Yue H, Lay T, Rivera L, et al. Rupture process of the $2010 \mathrm{Mw} 7.8$ Mentawai tsunami earthquake from joint inversion of nearfield GPS and teleseismic body wave recordings constrained by tsunami observations. J Geophys Res-Solid Earth, 2015, 119: 5574-5593

166 Deng Q D, Cheng S P, Ma J, et al. Seismic activities and earthquake potential in the Tibetan Plateau (in Chinese). Chin J Geophys, 2014, 57: 2025-2042 [邓起东, 程绍平, 马冀, 等. 青藏高原地震活动特征及当前地震活动形势. 地球物理学报, 2014, 57: 2025-2042]

167 Ding L. Nepal earthquake leads the south extrustion of Himalyayas (in Chinese). Chin Nat Geogr, 2015, 8: 156-163 [丁林. 尼泊尔大地 震令喜马拉雅山向南推开. 中国国家地理, 2015, 8: 156-163]

168 Teng J W. Ponder and research on the genesis and occurrence of strong earthquakes and the prediction of their place, time and intensity (in Chinese). Chin J Geophys, 2010, 53: 1749-1766 [滕吉文. 强烈地震孕育与发生的地点、时间及强度预测的思考与探讨. 地球物 理学报, 2010, 53: 1749-1766]

169 Teng J W, Ma X Y, Zhang X M, et al. Deep processes and dynamic responses of the generation and occurrence of the $2015 \mathrm{Nepal} M_{\mathrm{S}} 8.1$ earthquake (in Chinese). Chin J Geophys, 2017, 60: 123-141 [滕吉文, 马学英, 张雪梅, 等. 2015 年尼泊尔 $M_{\mathrm{S}} 8.1$ 大地震孕育的深层 过程与发生的动力学响应. 地球物理学报, 2017, 60: 123-141]

170 Teng J W, Ruan X M, Zhang Y Q, et al. The stratificational velocity structure of crust and covering strata of upper mantle and the orbit of deep interaquifer substance locus of movement for Tibetan Plateau (in Chinese). Chin J Geophys, 2012, 28: 4077-4100 [滕吉文, 阮 小敏, 张永谦, 等. 青藏高原地壳与上地幔成层速度结构与深部层间物质的运移轨迹. 岩石学报, 2012, 28: 4077-4100]

171 Teng J W, Wang Q S, Wang G J, et al. Specific gravity field and deep crustal structure of the "Himalayas east structural knot" (in Chinese). Chin J Geophys, 2006, 49: 1045-1052 [滕吉文, 王谦身, 王光杰, 等. 喜马拉雅“东构造结”地区的特异重力场与深部地壳结 构. 地球物理学报, 2006, 49: 1045-1052]

\section{补充材料}

图 S1 川滇及邻区深部视密度和主要断裂带分布图

图 S2 阿坝-理县-双流地带壳、幔结构剖面图( $\left.\mathrm{BB}^{\prime}\right)$

图 S3 2008 汶川-映秀 $M_{\mathrm{S}} 8.0$ 大地震深部介质破裂效应

图 S4 汶川 $M_{\mathrm{S}} 8.0$ 大地震和余震震源深度分布图

图 S5 汶川 $M_{\mathrm{S}} 8.0$ 地震及其余震重新定位震中分布及余震空间分段特征

图 S6 汶川-映秀 $M_{\mathrm{S}} 8.0$ 大地震发生后穿过龙门山断裂系的 NE 向余震震源深度剖面

本文以上补充材料见网络版 csb.scichina.com. 补充材料为作者提供的原始数据, 作者对其学术质量和内容负责. 


\title{
Geophysical background field and deep dynamics of the Wenchuan-Yingxiu $M_{\mathrm{S}} 8.0$ earthquake
}

\author{
Jiwen Teng ${ }^{1,2,3^{*}}$, Penghan Song ${ }^{1,3}$ \& Youshan Liu ${ }^{1}$ \\ ${ }^{1}$ Institute of Geology and Geophysics, Chinese Academy of Sciences, Beijing 100029, China; \\ ${ }^{2}$ College of GeoExploration Sicence and Technology, Jilin University, Changchun 100044, China; \\ ${ }^{3}$ University of Chinese Academy of Sciences, Beijing 100049, China \\ * Corresponding author, E-mail: jwteng@mail.iggcas.ac.cn
}

The Wenchuan-Yingxiu $M_{\mathrm{S}} 8.0$ earthquake occurred along the Longmenshan fault system where the tectonic and seismic activities are relatively less inactive than its surroundings. After the great earthquake, a dynamic failure corridor zone was formed at the surface, which was about $300 \mathrm{~km}$-long and $80 \mathrm{~km}$-wide and more than 70000 aftershocks occurred. The earthquake caused serious surface damages and large numbers of casualties, but no confirmed precursor phenomena were reported. In the northeastern Tibetan Plateau, geophysicists had applied many kinds of geophysical methods, including the artificial seismic probing, the natural seismic imaging, the gravity probing, and the electric and magnetic methods. Many researchers believed that the crust or mantle shortening is the main dynamic of the $M_{\mathrm{S}} 8.0$ Wenchuan-Yingxiu earthquake. However, the evidences were not enough, due to the disadvantage of the geophysical methods, such as the dubious resolution problem and the ambiguous interpretation from colorful results.

Based on the previous results and our extensively study, we made a further study on the Wenchuan-Yingxiu $M_{\mathrm{S}} 8.0$ earthquake which mainly concentrating on the three issues, including the highly isostatic equilibrium of the Longmenshan fault system, the fine structure and abrupt deep dynamics of the Longmenshan fault zone, and the force source system, the development and occurrence of the Wenchuan-Yingxiu $M_{\mathrm{S}} 8.0$ great earthquake. First, we reviewed the gravity filed and response of the boundary in the northeastern margin of Tibetan Plateau. The free-space and Bouguer gravity anomaly were given. The distribution of the theoretical isostatic crustal thickness and the isostatic thickness difference were analyzed. Considering the topography and gravity field of eastern Tibetan Plateau, the Longmenshan zone was far from gravity isostasy. Second, the electrical structures and the S-wave velocity structures were reviewed. We reanalyzed the four artificial seismic sounding profiles. Third, we showed a diagram of the $15 \pm 5 \mathrm{~km}$ deep convergence and the columnar force source of the seismogenic fault. Fourth, we summarized the three flow locus of deep matter in the eastern margin of Tibetan Plateau. Meanwhile, a model about the Wenchuan-Yingxiu $M_{\mathrm{S}} 8.0$ strong earthquake and deep material motion was proposed, illustrating the opposite motions of crust and upper mantle materials, and the strong collision between the crust of the Songpan-Gantze block and the Sichuan Basin.

We believe that the Wenchuan-Yingxiu $M_{\mathrm{S}} 8.0$ earthquake was caused by the collision and extrusion of the Indian plate and Eurasian plate which the east tectonic knot was extruding north under the Tibetan Plateau and the large force system intensified the tectonic and seismic activities in the east margin. In summary, we illustrated the processes as follows. (1) The crust and mantle material in the central Tibetan Plateau was blocked in the east which resulted a large-scale stress concentration and strong exchange of deep materials and energy. The variation of the crustal thickness between the northeastern Tibetan Plateau and the Sichuan Basin was large as 15-20 km. (2) The structures and properties of the material in the deep source mutated and leaded to a highly disequilibrium of gravity field. (3) Blocked by the hard crust of the Sichuan Basin, the low velocity crust and mantle materials beneath the western Sichuan Plateau thrusted upward along the steep fault plane of the Longmengshan fault and collided at the convergence spot of the three west-dipped fault planes. (4) The three surficial faults in the Longmenshan fault zone were not the seismogenic faults, but the convergence fault at the depth of $15 \pm 5 \mathrm{~km}$. The convergence fault was a columnar focal volume, which had a radius of $5 \mathrm{~km}$ and a length of $300 \mathrm{~km}$. The convergence of the fault planes in the deep focus induced the seismogenic fracture of the $M_{\mathrm{S}} 8.0$ Wenchuan-Yingxiu earthquake.

Wenchuan-Yingxiu $M_{\mathrm{S}} 8.0$ earthquake, exchange of materials and energy, mutation of crust and mantle structure, gravity disequilibrium, deep convergence fracture-seismogenic fracture

doi: 10.1360/N972018-00397 